\title{
Article \\ Modelling the Heating Process in the Transient and Steady State of an In Situ Tape-Laying Machine Head
}

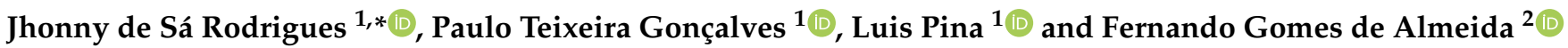 \\ 1 Institute of Science and Innovation in Mechanical and Industrial Engineering (INEGI), Rua Dr. Roberto Frias, \\ 4200-465 Porto, Portugal; prgoncalves@inegi.up.pt (P.T.G.); luismppina@gmail.com (L.P.) \\ 2 LAETA-INEGI, Faculty of Engineering, University of Porto, Rua Dr. Roberto Frias, s/n, \\ 4200-465 Porto, Portugal; fga@fe.up.pt \\ * Correspondence: jsrodrigues@inegi.up.pt
}

check for

updates

Citation: de Sá Rodrigues, J.;

Gonçalves, P.T.; Pina, L.; Gomes de Almeida, F. Modelling the Heating Process in the Transient and Steady State of an In Situ Tape-Laying Machine Head. J. Manuf. Mater. Process. 2022, 6, 8. https:// doi.org/10.3390/jmmp6010008

Academic Editors: Arkadiusz Gola, Izabela Nielsen and Patrik Grznár

Received: 24 November 2021

Accepted: 7 January 2022

Published: 11 January 2022

Publisher's Note: MDPI stays neutral with regard to jurisdictional claims in published maps and institutional affiliations.

Copyright: (c) 2022 by the authors. Licensee MDPI, Basel, Switzerland. This article is an open access article distributed under the terms and conditions of the Creative Commons Attribution (CC BY) license (https:/ / creativecommons.org/licenses/by/ $4.0 /)$.

\begin{abstract}
As the use of composite materials increases, the search for suitable automated processes gains relevance for guaranteeing production quality by ensuring the uniformity of the process, minimizing the amount of scrap generated, and reducing the time and energy consumption. Limitations on production by traditional means such as hand lay-up, vacuum bagging, and in-autoclave methods tend not to be as efficient when the size and shape complexity of the part being produced increases, motivating the search for alternative processes such as automated tape laying (ATL). This work aims to describe the process of modelling and simulating a composite ATL with in situ consolidation by characterizing the machine elements and using the finite differences method in conjunction with energy balances in order to create a digital twin of the process for further control design. The modelling approach implemented is able to follow the process dynamics when changes are made to the heating element and to predict the composite material temperature response, making it suitable for use as a digital twin of a production process using an ATL machine.
\end{abstract}

Keywords: automatic fiber laying; thermoplastic composites; process simulation; digital twin

\section{Introduction and Related Works}

The search for more efficient and automated manufacturing processes for composite materials has found that the automated tape-laying (ATL) process with in situ consolidation for thermoplastic laminates is a good alternative for reducing material scrap and increasing the manufacturability of complex geometries by out-of-autoclave processes [1-4].

This process requires a machine mainly made up of a heating source and a compaction mechanism in order to raise the composite temperature, guaranteeing the quality of the final part by ensuring that all the laid composite layers have been welded among themselves [5]. The main parameters that affect the quality of the final product are the temperature and the compaction roll pressure at the nip point $[3,6]$. The temperature is the most critical parameter that must be controlled in order to reduce defects such as voids or delamination.

The heating process is the most critical stage. Reaching the necessary composite temperature ensures a good bonding condition between the layers $[7,8]$. The exposure of the thermoplastic matrix to inadequate temperatures may cause the degradation of the material and residual thermal stresses [2,9-11], making the final part defective and unable to meet the required performance.

Most modelling works focussing on the use of a heating head for the tape-laying process that can be found in the literature use lasers as heat sources [12-14] due to their controlled power delivery at a fixed wavelength and localized region. The position of the heat source relative to the composite tape is one of the most relevant parameters, as presented by [15], because the heating process depends on optical properties such as reflectivity for the head assembly, the wavelength absortibity of the heated material, and surface irregularities. 
Other studies using similar heat sources study the temperature distribution by measuring the temperature just before the nip point using thermal cameras [16] and analysing the results for three different power values of the heat source. The authors of [4] propose a model that uses lasers to heat a set of thinner composite tapes in order to study the influence of the width of the tapes on the overall heating process when the machine has to follow a non straight path.

Another heat source used for this process is hot gas torches [14,17], where the heat transfer into the composite mainly depends on the convection coefficient computed using empirical correlations.

A study that is not related to the manufacturing of composite materials and that discusses the topic of heat sources was carried out by $[18,19]$. This work presents a strategy to model a radiation heat source using infrared lamps for a continuous paper drying process. This work suggests an energy balance between the process parts involved, taking into account their properties.

Independently of the heat source, all models share the same phenomenological problem-that is, understanding the temperature response of the composite material during the process. The majority of authors in this field have focussed on numerical and experimental studies of the problem, assuming constant process parameters such as heat power and feed velocity without considering the use of control strategies to improve the overall process by adjusting its parameters.

Another common characteristic of the models proposed in the literature is related to the mathematical approach used. The use of a three-dimensional heat exchange was proposed by [20]; this implies a high computational cost that increases when the model results are used in combination with resin cure models, as proposed by [21]. A simplified model was proposed by [22]; this model uses a hot air gun as a heating source, in which a $1.5 \mathrm{D}$ thermal approach is used; this model does not take into account variations in the material properties with temperature. On the other hand, an analytical model was developed by [23]; this approach relates process parameters such as laser beam power, process speed, and mold temperature, regardless of the geometrical characteristics of the material being processed. This analytical approximation makes assumptions such as uniform heat flux exposition, no heat loss to the environment, and constant thermophysical properties.

This work focuses on the development of a digital twin model for an automated tape-laying (ATL) machine. The model takes into account the heat source, the composite material, the compaction roll, and the surroundings as an enclosure to study the temperature distribution along the material under different process conditions. The mathematical model is 1.5 dimensional, as both the material and the reflector thickness are modelled with only one element in that direction. The thermo-optical properties of the elements with its temperature dependence were also considered within the infrared range to obtain an accurate description of the process response.

In Section 2, the ATL machine head components are described. Section 3 presents a 1.5 dimensional mathematical model for the components described in the previous section, emphasising the radiation heat exchange model, which involves optical and temperature dependant properties as well as their spatial distribution. In this, a mathematical model for the material machine processes is also presented. Section 4 presents the thermal properties equations for the machine head elements as a function of temperature. Section 5 presents the composite material to be used in terms of its thermal and optical properties; it also presents the equation solver method to simulate the ATL process and describes a strategy that can be used to measure the ATL process variables needed to feed the mathematical model. Section 6 presents the model validation by comparing the obtained measurements of the ATL process variables with the results calculated using the mathematical model.

\section{The ATL Machine Head}

The main components of the machine head assembly, numbered from 1 to 5 in Figure 1 , are: (1) a material feeder, consisting of an unwinding mechanism that keeps the material 
straight along its pathway through the heating section; (2) a heat source, consisting of an infrared lamp and (3) a back plate that acts as a reflector; (4) an optical temperature sensor that is used to measure the material temperature; (5) a compaction roll in which a fluid circulates at a controlled temperature and presses the heated material against (6) a mold.

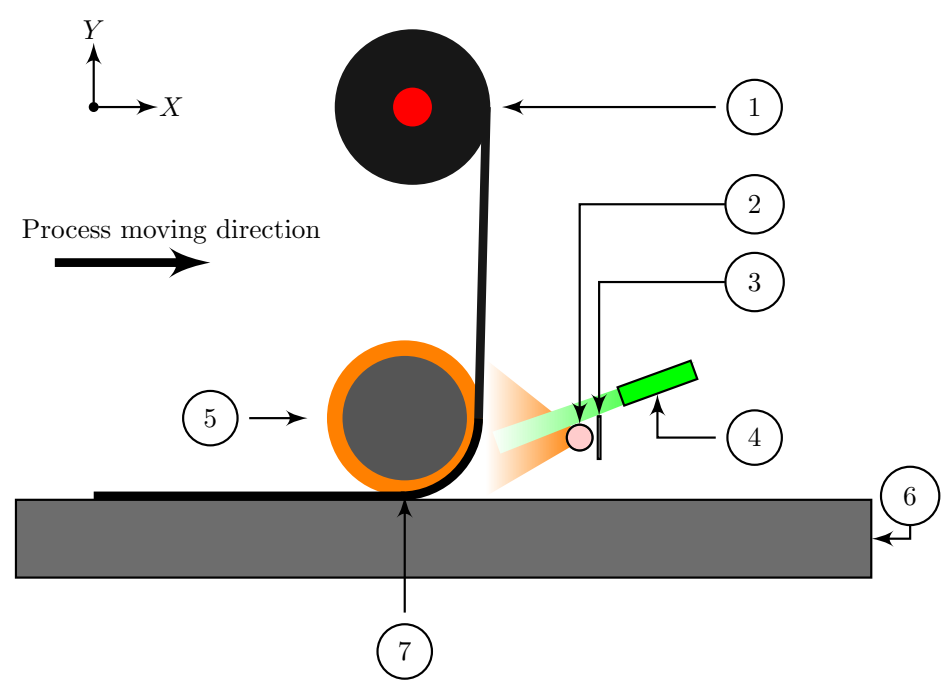

Figure 1. Machine head assembly. (1) Material feeder. (2) Heating element. (3) Reflector. (4) Optical temperature sensor. (5) Compaction roll. (6) Mold. (7) Nip point.

The goal of the machine head is to create a laminate by heating up a continuous material tape to a temperature above its melting point that is to be welded to a previous material layer or the mold (if it is the first layer of the process) near the nip point, as shown in Figure 1.

\subsection{Infrared Heating Element}

The infrared heater in the machine head assembly consists of a tungsten filament coil heated by an electric current that serves as the emitter. This emitter is surrounded by a quartz glass envelope. This quartz glass acts as an enclosure containing an inert gas to prevent filament oxidation at high temperatures as well as small amounts of halogen to inhibit the evaporation of tungsten via the halogen cycle.

To maintain the atmosphere inside the quartz envelope, the current is passed through a pair of Molybdenum foil pads, ensuring the gas chamber is sealed to the outside atmosphere, for an increased service life. Figure 2 shows the heating element assembly.

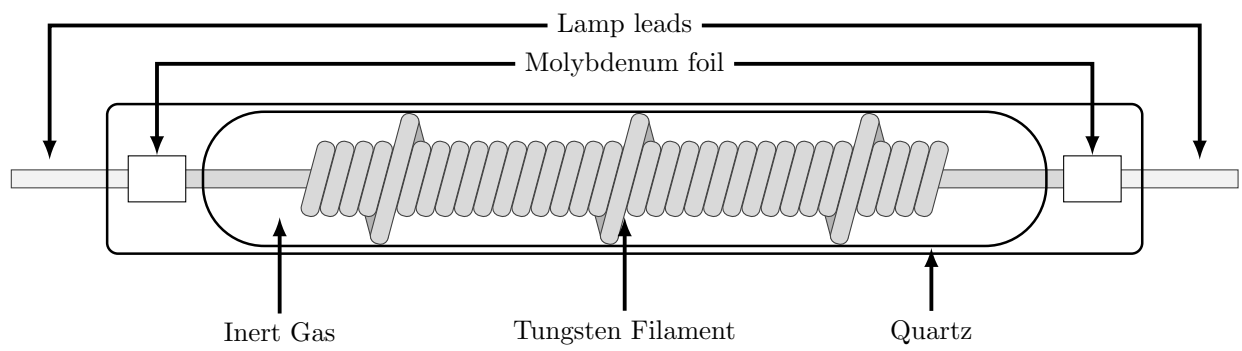

Figure 2. Heating element and its cross section.

\subsection{Compaction Roll}

The compaction roll is a cylinder that rotates with the motion of the entire machine head assembly while applying a fixed amount of pressure on top of the new material layer and the previous laid one, or the mold surface for the case of the first laid material, ensuring a contact bonding between the two surfaces at the nip point. To avoid any damage being caused to the heated material by the cylinder, a $5 \mathrm{~mm}$ coating of silicone rubber from 
Silex [24] covers the $100 \mathrm{~mm}$ diameter aluminium cylinder, preventing it from sticking to the material matrix during the process. On the other hand, to avoid the overheating of the compaction roll silicon cover, a fluid is circulated through the metal housing of the cylinder to control its temperature, which, according to the silicon manufacturer, can reach a maximum of $300^{\circ} \mathrm{C}$.

\subsection{Material Feeder}

The material feeder consists of a cylinder with a tension mechanism that ensures the material roll placed around it will always be in tension while it is being fed towards the compaction roll.

\section{1.5D Mathematical Model for the ATL Heating Process}

As stated in the previous section, the ATL head is mainly made up of an infrared lamp acting as a heating element with an aluminum back plate acting as a radiation reflector and a consolidation roll that presses the heated material against the mold. The process involves two main phenomenons-namely, the heating process to achieve the adequate consolidation temperature in the incoming material and the consolidation process itself.

In this work, we focus on the heating process of the incoming material because this is the most critical to the process quality $[8,11,25,26]$. Both the reflector and the material will be modelled using a single element along its thickness. For the reflector, as its main function is to redirect the heating energy towards the material, it is not necessary to know the temperature distribution along its thickness; a compensation factor is implemented for heat losses due to convection at the surface facing the composite material and at the opposite surface. For the material, its thickness is significantly smaller than its length, meaning that the temperature gradient along its thickness is negligible. Hence, a 1.5D heat transfer model of the ATL head is used to develop a process digital twin, which would allow us to run simulations and design proper control strategies.

Figure 1 presents the layout of the machine head assembly. It moves horizontally, parallel to the heated mold, and the material is fed vertically to the compaction roll, which changes its orientation to horizontal when the nip point is reached. This causes the material feed velocity to match the machine head assembly velocity. The other assembly elements, such as the infrared lamp, reflector, compaction roll, and optical temperature sensor, move horizontally along with the machine head.

Understanding the relative movements between the machine head components and the material is relevant, as this determines the selection of the appropriate correlation for estimating the convection coefficients.

Figure 3 shows a schematic of the simplified model of the ATL presented in the previous section. The curved path was simplified to a straight line, where $y_{\text {convection }}$ corresponds to the region before reaching the roll, $y_{\text {roll }}$ corresponds to the curved path in contact with the roll with its equivalent length, and $y_{\text {mold }}$ corresponds to the region after the nip point.

The ATL model involves an open-cavity radiation problem where the heat emitted by the lamp and reflected by the reflector is used to increase the temperature of the entering material tape before it reaches the nip point. Ambient heat loss due to convection and radiation also takes place and is considered in the model.

Figure 3 shows three different zones of heat exchange over the material: The first one, delimited by $y_{\text {convection, }}$ involves radiation from the lamp and convection to the surrounding air, for which the convection coefficient depends on the air temperature and air flow velocity and direction. The second one, delimited by $y_{\text {roll }}$, involves heat exchange from radiation, convection, and conduction to the compaction roll. The third zone, delimited by $y_{\text {mold }}$, involves only conduction to both the compaction roll and mold.

To develop the proposed model, all of the components are analyzed to obtain the governing equations and the corresponding finite differences schemes, following a similar 
approach to that presented in the literature by [18] to obtain a mathematical expression based on the literature, as follows.

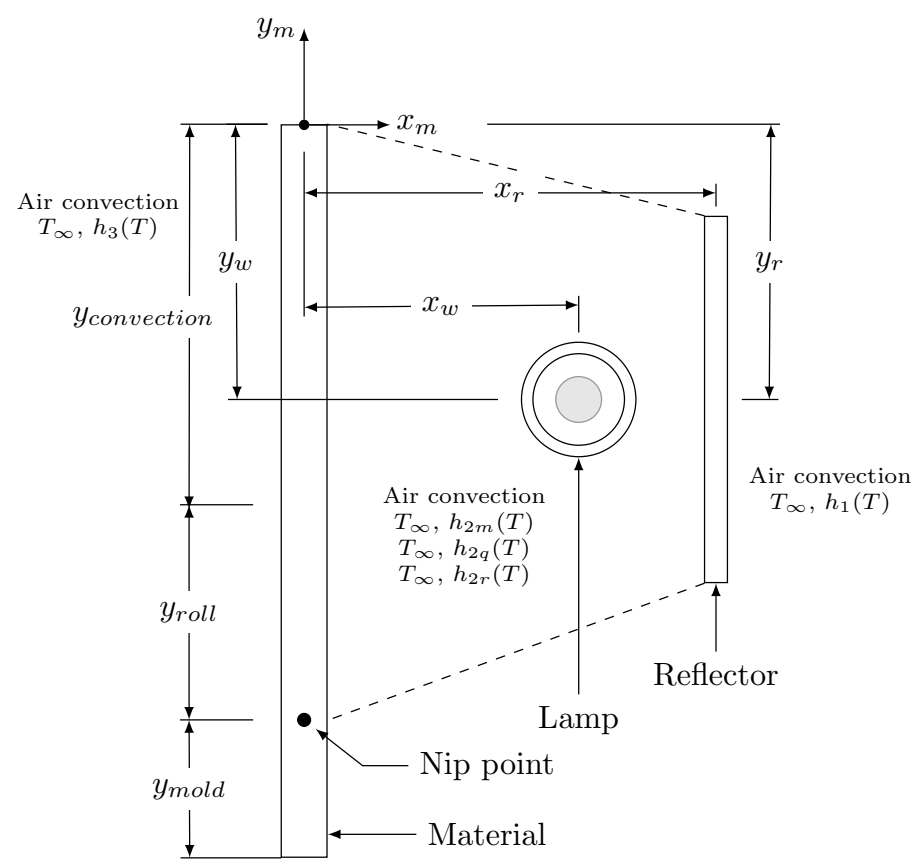

Figure 3. 1.5D model schematic.

\subsection{Heater}

The heater element is a halogen lamp composed of a tungsten filament enclosed by a cylindrical quartz envelope filled with neon gas. A simplification of the lamp geometry is presented in Figure 4, where the concentric arrangement of the components was proposed by [18]. Figure $4 \mathrm{a}$ presents a front view of the lamp model as the tungsten is modeled as a solid cylinder of length $l_{w}$ and diameter $d_{c o i l}$ as a simplification of its spiral construction (Figure 4c), while the quartz envelope is modeled as a hollow cylinder of length $l_{q}$, thickness $t_{q}$ (Figure $4 \mathrm{a}$ ), and external diameter $d_{l}$ (Figure $4 \mathrm{~b}$ ).

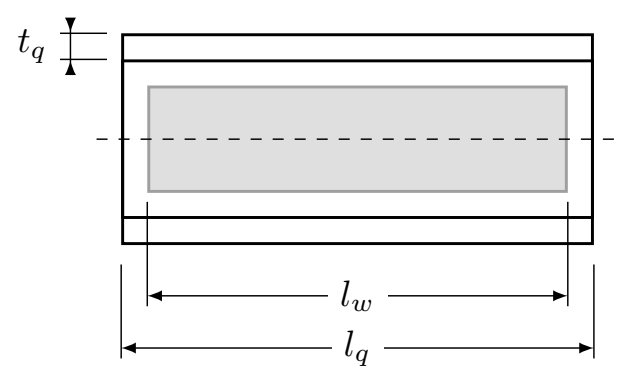

(a)

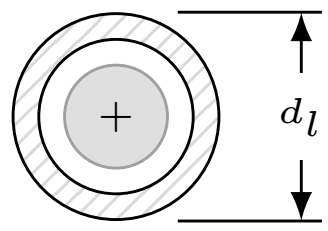

(b)

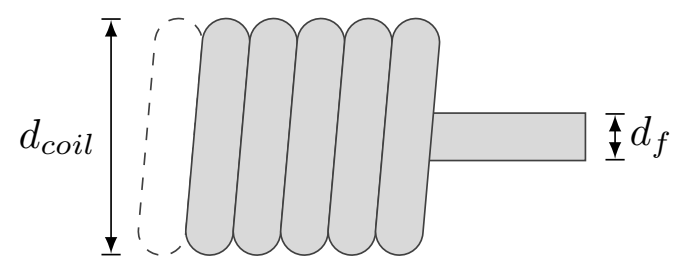

(c)

Figure 4. Lamp model. (a) Lamp model front view. (b) Lamp model cross section. (c) Filament model. 


\subsubsection{Tungsten Filament}

The tungsten filament is considered as an homogeneous element with an internal heat generation given by its electrical resistance, which is a function of temperature $T_{f}$, and the applied voltage. It exchanges heat with the neon by conduction and with the inner face of the quartz lamp by radiation. No convection between the filament and the neon is considered because of the low value for the Grashof number, as suggested by [18], indicating conduction to be the predominant phenomenon in this particular heat exchange process. The heat transfer model used for the tungsten filament includes the energy balance given in (1) $[27,28]$,

$$
m_{f} c p_{f}\left(T_{f}\right) \frac{d T_{f}}{d t}=\left(P_{e l}-Q_{r, f}-Q_{c, n}\right)
$$

where:

- $\quad m_{f}$ : Filament mass, kg.

- $T_{f}$ : Filament temperature, $\mathrm{K}$.

- $\quad c p_{f}\left(T_{f}\right)$ : Filament specific heat (temperature dependent), $\left[\frac{\mathrm{J}}{\mathrm{kg} \cdot \mathrm{K}}\right]$.

- $\quad P_{e l}$ : Electric power, W.

- $Q_{r, f}$ : Radiation heat, W.

- $Q_{c, n}$ : Conduction heat, W.

The electric power of the resistance, can be expressed using (2):

$$
P_{e l}=\frac{U_{e}^{2}}{R\left(T_{f}\right)}
$$

where $U_{e}$ stands for the applied voltage. The electrical resistance $R\left(T_{f}\right)$ can be expressed as a function of the resistivity, filament length $l_{f}$, and filament cross-sectional area $a_{f}(3)$.

$$
R\left(T_{f}\right)=r_{w}\left(T_{f}\right) \frac{l_{f}\left(T_{f}\right)}{a_{f}\left(T_{f}\right)}
$$

\subsubsection{Neon}

The neon has a very low thermal capacitance compared to the tungsten and quartz; hence, its thermal capacitance is neglected. Accordingly, the neon transfers heat from the tungsten to the lamp internal surface by conduction. Taking advantage of the cylindrical configuration, the heat conducted by the neon can be approximated using the cylindrical solution for radial conduction (4), as suggested by [18,27].

$$
Q_{c, n}=2 \cdot \pi \cdot l_{q} \cdot K_{n}\left(T_{n}\right) \cdot \frac{\left(T_{f}-T_{q}\right)}{\ln \left(\frac{d_{L}}{d_{c o i l}}\right)}
$$

where:

- $Q_{c, n}$ : Conduction heat, W.

- $K_{n}\left(T_{n}\right)$ : Neon conductivity (temperature dependent), $\left[\frac{\mathrm{W}}{\mathrm{m} \cdot \mathrm{K}}\right]$.

- $T_{n}$ : Neon mean temperature $\left(\frac{T_{f}-T_{q}}{2}\right), \mathrm{K}$.

- $T_{q}$ : Quartz lamp temperature, K.

- $d_{L}$ : Lamp diameter, $\mathrm{m}$.

- $d_{\text {coil }}$ : Filament coil diameter, $\mathrm{m}$.

- $l_{q}$ : Lamp length, m. 


\subsubsection{Quartz Glass Envelope}

The quartz envelope is considered to have a constant temperature $T_{q}$ across the thickness because it has a small thickness. The energy balance for the envelope is given in (5), as suggested by [18].

$$
m_{q} \cdot c p_{q}\left(T_{q}\right) \cdot \frac{d T_{q}}{d t}=\left(Q_{r, f}+Q_{c, n}-Q_{r, q}-h_{2 q} A_{q}\left(T_{q}-T_{\infty}\right)\right)
$$

where:

- $\quad m_{q}$ : Quartz cylinder mass, $\mathrm{kg}$.

- $\quad c p_{q}\left(T_{q}\right)$ : Quartz specific heat, $\left[\frac{\mathrm{J}}{\mathrm{kg} \cdot \mathrm{K}}\right]$.

- $Q_{r, f}:$ Incoming radiation heat, $\mathrm{W}$.

- $Q_{r, q}$ : Outgoing radiation heat, $\mathrm{W}$.

- $Q_{c, n}$ : Conduction heat, $\mathrm{W}$.

- $\quad h_{2 q}$ : Convection coefficient, $\left[\frac{\mathrm{W}}{\mathrm{m}^{2} \mathrm{~K}}\right]$.

- $A_{q}$ : Quartz surface area, $\mathrm{m}^{2}$.

- $T_{\infty}$ : Air Temperature inside the radiation cavity, $\mathrm{K}$

Some of the data required for the lamp simulation are expressed in Table 1 from measurements performed on a series of lamps.

Table 1. Measurements for the lamp characteristics.

\begin{tabular}{cc}
\hline Lamp Property & Measured Value \\
\hline Lamp length & $189.02 \mathrm{~mm} \pm 0.34 \mathrm{~mm}$ \\
Lamp diameter & $10.01 \mathrm{~mm} \pm 0.19 \mathrm{~mm}$ \\
Lamp resistance $\left(\right.$ at $\left.23^{\circ} \mathrm{C}\right)$ & $9.6 \Omega \pm 6.41 \cdot 10^{-6} \Omega$ \\
Filament diameter & $0.410 \mathrm{~mm} \pm 0.004 \mathrm{~mm}$ \\
Filament coil diameter & $2.890 \mathrm{~mm} \pm 0.004 \mathrm{~mm}$ \\
Filament coil length & $290.04 \mathrm{~mm} \pm 0.37 \mathrm{~mm}$ \\
Filament mass & $5.2019 \mathrm{~g} \pm 0.0005 \mathrm{~g}$ \\
Lamp glass mass & $13.8780 \mathrm{~g} \pm 0.0005 \mathrm{~g}$ \\
\hline
\end{tabular}

\subsection{Reflector}

The lamp reflector is considered as a thin metal sheet with a constant temperature across thickness $t_{r}$; it is modelled as a 1.5D finite volume problem along its width $W_{r}$. The reflector transfers heat with the ambient air at its right hand side surface $\left(T_{\infty}, h_{1}(T)\right)$, transfers heat with the internal air in the cavity $\left(T_{\infty}, h_{2 r}(T)\right)$, and reflects radiation heat from the lamp. An energy balance over a reflector cell of volume $V_{r}$ is given in (6), taking into account its surfaces $S_{r}$ for heat exchange.

$$
\begin{aligned}
\frac{\partial}{\partial t} \int_{V_{r}} \rho_{r} \cdot c p_{r}\left(T_{r}\right) c d o t T_{r} \cdot d V_{r}= & \int_{\partial V_{r}} k_{r}\left(T_{r}\right) \cdot\left(\nabla T_{r} \cdot \hat{n}\right) \cdot d S_{r} \\
& +\int_{\partial V_{r}} q_{r a d, r}^{\prime \prime} \cdot d S_{r}+\int_{\partial V_{r}} q_{c o n v, r}^{\prime \prime} \cdot d S_{r}
\end{aligned}
$$

where:

- $\rho_{r}$ : Reflector material density, $\left[\frac{\mathrm{kg}}{\mathrm{m}^{3}}\right]$.

- $T_{r}$ : Reflector temperature, $\mathrm{K}$.

- $\quad c p_{r}\left(T_{r}\right)$ : Reflector specific heat (temperature dependent), $\left[\frac{\mathrm{J}}{\mathrm{kg} \cdot \mathrm{K}}\right]$.

- $k_{r}\left(T_{r}\right)$ : Reflector conductivity (temperature dependent), $\left[\frac{\mathrm{W}}{\mathrm{m} \cdot \mathrm{K}}\right]$.

- $q_{r a d, r}^{\prime \prime}\left(T_{r}\right)$ : Radiation heat, $\left[\frac{\mathrm{W}}{\mathrm{m}^{2}}\right]$. 
- $\quad q_{c o n v, r}^{\prime \prime}\left(T_{r}, T_{\infty}\right)$ : Convection heat $\left[\frac{\mathrm{W}}{\mathrm{m}^{2}}\right]$.

A finite volume technique is used to discretize the lamp reflector geometry, as shown in Figure 5. The application of the energy balance to each reflector cell gives the cell equation (7) for the unknown cell temperature, with the coefficients given by (8) through (11). The material properties inside the volume cell are constant and are evaluated at the nodal temperature.

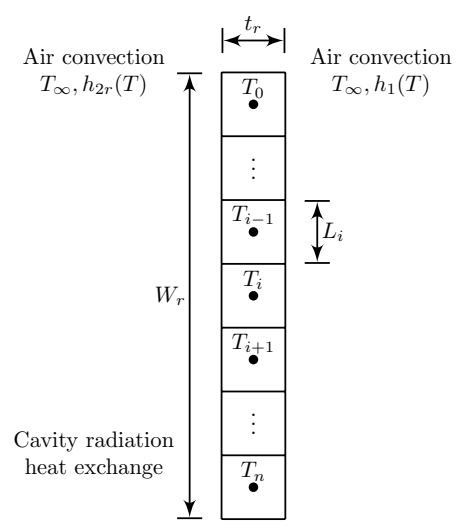

Figure 5. The 1.5D model for the reflector.

$$
\dot{T}_{r}=\left(A_{r}\right) T_{r-1}-\left(2 A_{r}+B_{r, 1}+B_{r, 2}\right) T_{r}+\left(A_{r}\right) T_{r+1}+\left(B_{r, 1}\right) T_{\infty, 1}+\left(B_{r, 2}\right) T_{\infty, 2}+\left(C_{r}\right) q_{r a d, r}^{\prime \prime}\left(T_{r}\right)
$$

with:

$$
\begin{aligned}
A_{r} & =\frac{k_{r}\left(T_{r}\right)}{\rho_{r} \cdot c p_{r}\left(T_{r}\right) \cdot L_{r}^{2}} \\
B_{r, 1} & =\frac{h_{1}}{\rho_{r} \cdot c p_{r}\left(T_{r}\right) \cdot t_{r}} \\
B_{r, 2} & =\frac{h_{2 r}}{\rho_{r} \cdot c p_{r}\left(T_{r}\right) \cdot t_{r}} \\
C_{r} & =\frac{1}{\rho_{r} \cdot c p_{r}\left(T_{r}\right) \cdot t_{r}}
\end{aligned}
$$

where:

- $\quad r$ : Reflector cell number $0,1, \ldots, \mathrm{n}$.

- $L_{r}$ : Length of reflector cell, $\mathrm{m}$.

- $t_{r}$ : Reflector thickness, $\mathrm{m}$.

- $T_{\infty}$ : Air temperature, $\mathrm{K}$.

- $h_{1}\left(T_{r}, T_{\infty}\right)$ : External convection coefficient, $\left[\frac{\mathrm{W}}{\mathrm{m}^{2} \cdot \mathrm{K}}\right]$.

- $\quad h_{2 r}\left(T_{r}, T_{\infty}\right)$ : Internal convection coefficient, $\left[\frac{\mathrm{W}}{\mathrm{m}^{2} \cdot \mathrm{K}}\right]$.

The lateral conditions for the reflector are defined as adiabatic (12a) (12b) due to $W_{r} \gg t_{r}$, making the heat exchange in those surfaces negligible in comparison with the heat exchange of the remaining surfaces.

$$
\begin{aligned}
& \left.\frac{\partial T}{\partial y}\right|_{y=0}=0 \\
& \left.\frac{\partial T}{\partial y}\right|_{y=W_{r}}=0
\end{aligned}
$$




\subsection{Material}

The material fiber tape is placed at a velocity $U$ over a mold at a constant temperature $T_{\text {mold }}$ while it is heated by the lamp. The material domain begins at the section where the material is fed $\left(Z_{1}\right)$, exchanging heat by radiation and convection, followed by the section $Z_{2}$, where heat transfer also occurs by conduction due to the contact between the material and the compaction roll. This ends with $Z_{3}$, where the consolidation point its located.

The tape is considered as a thin sheet with a constant temperature across its thickness and supplied at a constant temperature $T_{0}$. The energy balance for a cell volume $V_{m}$ of the material tape is given in (13):

$$
\begin{aligned}
& \frac{\partial}{\partial t} \int_{V_{m}} \rho_{m} \cdot c p_{m}\left(T_{m}\right) \cdot T_{m} \cdot d V_{m}=\int_{\partial V_{m}} k_{m}\left(T_{m}\right) \cdot\left(\nabla T_{m} \cdot \hat{n}\right) \cdot d S_{m} \\
& -\int_{\partial V_{m}} \rho_{m} \cdot c p_{m}\left(T_{m}\right) \cdot T_{m} \cdot(U \cdot \hat{n}) \cdot d S_{m} \\
& +\int_{\partial V_{m}} q_{r a d, m}^{\prime \prime} \cdot d S_{m}+\int_{\partial V_{m}} q_{c o n v, m}^{\prime \prime} \cdot d S_{m}+\int_{\partial V_{m}} q_{c o n d, m}^{\prime \prime} \cdot d S_{m}
\end{aligned}
$$

where:

- $\rho_{m}$ : Composite material density, $\left[\frac{\mathrm{kg}}{\mathrm{m}^{3}}\right]$.

- $T_{m}$ : Material Temperature, $\mathrm{K}$.

- $\quad c p_{m}\left(T_{m}\right)$ : Composite specific heat (temperature dependent), $\left[\frac{\mathrm{J}}{\mathrm{kg} \cdot \mathrm{K}}\right]$.

- $\quad k_{m}\left(T_{m}\right)$ : Composite conductivity (temperature dependent), $\left[\frac{\mathrm{W}}{\mathrm{m} \cdot \mathrm{K}}\right]$.

- $\quad q_{r a d, m}^{\prime \prime}\left(T_{m}\right)$ : Radiation heat, $\left[\frac{\mathrm{W}}{\mathrm{m}^{2}}\right]$.

- $\quad q_{\text {conv }, m}^{\prime \prime}\left(T_{m}, T_{\infty}\right):$ Convection heat, $\left[\frac{\mathrm{W}}{\mathrm{m}^{2}}\right]$.

- $\quad q_{\text {cond, } m}^{\prime \prime}\left(T_{m}, T_{\text {mold }}\right)$ : Conduction heat, $\left[\frac{\mathrm{W}}{\mathrm{m}^{2}}\right]$.

A finite volume technique, as suggested by [13], is used to represent the tape geometry (see Figure 6), and the application of the energy balance to each tape cell gives the cell equation (14) for the unknown cell temperature using the coefficients given by (15) through (21).

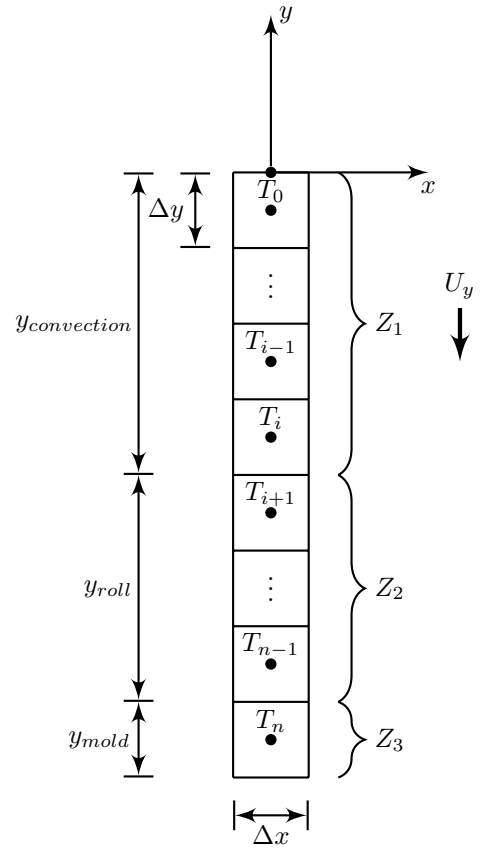

Figure 6. The 1.5D material model. 


$$
\begin{aligned}
& \dot{T}_{m}=\left(\left.A\right|_{Z_{1}, Z_{2}, Z_{3}}\right) \cdot T_{m+1}+\left(\left.A\right|_{Z_{1}, Z_{2}, Z_{3}}+\left.B\right|_{Z_{1}, Z_{2}, Z_{3}}\right) \cdot T_{m-1} \\
& +\left(-\left.2 A\right|_{Z_{1}, Z_{2}, Z_{3}}-\left.C 1\right|_{Z_{1}, Z_{2}}-\left.C 2\right|_{Z_{1}}-\left.D 1\right|_{Z_{2}}-\left.D 2\right|_{Z_{3}}\right) \cdot T_{m} \\
& +\left.C 1\right|_{Z_{1}, Z_{2}} \cdot T_{\infty}+\left.C 2\right|_{Z_{1}} \cdot T_{\infty}+\left.D 1\right|_{Z_{2}} \cdot T_{\text {roll }}+\left.D 2\right|_{Z_{3}} \cdot T_{\text {mold }} \\
& +\left.D 3\right|_{Z_{1}, Z_{2}} \cdot q_{\text {rad }}^{\prime \prime} \\
& A=\frac{k_{m}\left(T_{m}\right)}{\rho_{m} \cdot c p_{m}\left(T_{m}\right) \cdot \Delta y^{2}} \\
& B=\frac{U}{\Delta y} \\
& C 1=\frac{h_{2 m}}{\rho_{m} \cdot c p_{m}\left(T_{m}\right) \cdot \Delta x} \\
& C 2=\frac{h_{3} m}{\rho_{m} \cdot c p_{m}\left(T_{m}\right) \cdot \Delta x} \\
& D 1=\frac{1}{\rho_{m} \cdot c p_{m}\left(T_{m}\right) \cdot \Delta x \cdot R_{\text {roll }}} \\
& D 2=\frac{1}{\rho_{m} \cdot c p_{m}\left(T_{m}\right) \cdot \Delta x \cdot R_{\text {mold }}} \\
& D 3=\frac{1}{\rho_{m} \cdot c p_{m}\left(T_{m}\right) \cdot \Delta x}
\end{aligned}
$$

where:

- $\quad m$ : Material cell number $0,1, \ldots, \mathrm{n}$.

- $R_{\text {mold }}$ : Composite wall resistance for heat conduction between the mold and the material, $\left[\frac{\mathrm{m}^{2} \cdot \mathrm{K}}{W}\right]$.

- $\quad R_{\text {roll }}$ : Composite wall resistance for heat conduction between compaction roll and the material, $\left[\frac{\mathrm{m}^{2} \cdot \mathrm{K}}{W}\right]$.

- $\quad q_{\text {rad }}^{\prime \prime}$ : Net radiation from the surfaces involved in the heat exchange process, $\left[\frac{\mathrm{W}}{\mathrm{m}^{2}}\right]$.

- $h_{2 m}$ : Convection coefficient for the material surface facing the heating element, $\left[\frac{\mathrm{W}}{\mathrm{m}^{2}}\right]$.

The terms (15) through (21) are evaluated in (14), taking into account each material section $Z_{i}$, as shown in Figure 6. This allows us to obtain the corresponding boundary conditions for the cell. After evaluating all the terms for all the material cells, a system of differential equations is built to compute the new material temperatures.

At section $Z_{1}$, the material arrives at an initial temperature $T_{0}=T_{\infty}$, where convection $(C 1, C 2)$ and radiation (D3) are the main heat exchange phenomena. At this section, the convection's relation is defined using the inside enclosure air properties $\left(T_{\infty}, h_{2 m}\right)$, and the radiation phenomena are added to the balance to complete the relation. The radiation term added comes from an energy balance further discussed in this work; at section $Z_{2}$ radiation (D3), convection (C1), and conduction (D1) are the heat exchange phenomena present; at section $Z_{3}$ the material is located between the compaction roll and the mold, which means that conduction $(D 1, D 2)$ is the main heat exchange phenomena occurring between the compaction roll and the mold simultaneously. For this model, the temperature of the nip point is located at the material cell $T_{n}$, and the previously laid material temperature is modelled assuming a constant value of $T_{\text {mold }}$. The terms $R_{\text {mold }}$ and $R_{\text {roll }}$ are explained in the following section. 
The boundary condition related to the $y$ axis at the first material cell is represented using (22); the last material cell, in the same $y$ axis, is represented using (23).

$$
\begin{gathered}
\left.T\right|_{y=0}=T_{0} \\
\frac{\partial T}{\partial y}=0
\end{gathered}
$$

\subsection{Compaction Roll and Mold}

The compaction roll is used to press the incoming material, once heated, against the mold or the material previously laid during consolidation. It consists of a hollow aluminum cylinder in which water circulates at a constant temperature to avoid mechanical damage to the seals and bearings. The exterior of the cylinder is covered with a layer of solid high-temperature silicone rubber Silex GP60THT [24].

The model strategy used for simulating the heat exchange process between the compaction roll and the material uses a combination of a composite hollow cylinder with $1 \mathrm{D}$ radial conduction for the compaction roll internal fluid, the aluminium structure, and the rubber layer and the 1D conduction of a plane wall approximation for the material, as presented in [27], because the material is thinner than the rubber layer or even the aluminium structure of the cylinder, making the relation $\ln \left(\frac{D_{\text {roll }} / 2+t_{\text {rubber }}+\Delta x}{D_{\text {roll }} / 2+t_{\text {rubber }}}\right) \approx 0$, where $D_{\text {roll }}$ is the compaction roll diameter without the rubber layer, $t_{\text {rubber }}$ is the thickness of the rubber layer, and $\Delta x$ is the thickness of the material.

For the case presented at section $Z_{2}$ in Figure 6, the heat exchange phenomena are convection, radiation, and conduction. The energy balance for conduction to the compaction roll at this section can be obtained from Figure 7a, where the heat exchange by conduction is mathematically expressed as an array of resistors connected in series relations (24) and (25).

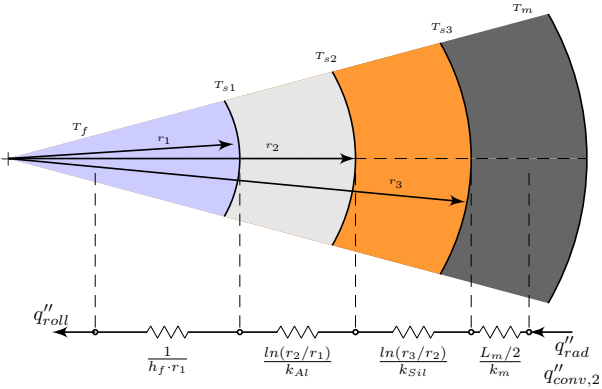

(a)
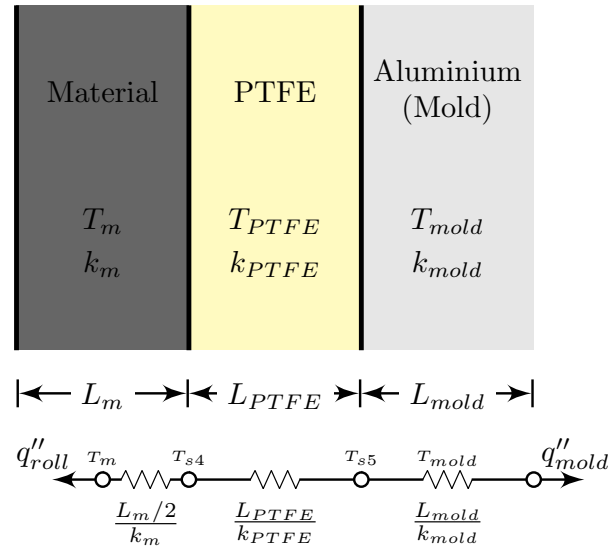

(b)

Figure 7. Composite wall for the heat conduction balance. (a) Composite wall model for the 1D compaction roll $D_{3}$. (b) The $1 \mathrm{D}$ compaction roll in section $D_{4}$.

$$
\begin{gathered}
R_{\text {roll }}=\frac{1}{h_{f} \cdot r_{1}}+\frac{\ln \left(r_{2} / r_{1}\right)}{k_{A l}}+\frac{\ln \left(r_{3} / r_{2}\right)}{k_{S i l}}+\frac{L_{m} / 2}{k_{m}} \\
R_{\text {roll }}=\frac{\ln \left(r_{2} / r_{1}\right)}{k_{A l}}+\frac{\ln \left(r_{3} / r_{2}\right)}{k_{\text {Sil }}}+\frac{L_{m} / 2}{k_{m}}
\end{gathered}
$$

From Figure 7a, the term $R_{\text {roll }}$ is deduced, taking into account the convection coefficient of the internal fluid (giving relation (24)). For a constant internal temperature, the relation can be deduced (25). 
At section $Z_{3}$ in Figure 6, the scheme for the energy balance involves conduction through the mold, as presented in Figure $7 \mathrm{~b}$. For the mold, a film of Polytetrafluoroethylene (PTFE) acting as a mold-releasing agent between the laid material and the moldit is considered; from Figure $7 \mathrm{~b}$, the term $R_{\text {mold }}$ gives the relation (26):

$$
R_{\text {mold }}=\frac{L_{m} / 2}{k_{m}}+\frac{L_{P T F E}}{k_{P T F E}}+\frac{L_{\text {mold }}}{k_{\text {mold }}}
$$

\subsection{Radiation}

Radiation as heat transfer has been well studied when gray surfaces participate inside an enclosure; it has been described in several text books [27-30] and by several researchers [18,31-33]. For this work, the general enclosure is described in Figure 3, where the reflector, the lamp, and the material are involved. The dashed lines represent a hypothetical surface acting as the surroundings of the enclosure. In order to simplify calculations, the radiation flux problem is modeled as a two-dimensional system allowing one to calculate the heat flux per unit area; Equations (7) and (14) can be solved using the radiation heat input expressed in $\left(\mathrm{W} / \mathrm{m}^{2}\right)$. It is worth mentioning that the view factors for two-dimensional problems have been well studied and equations have been developed to simplify the calculations [28-30,33,34], these equations are discussed further in this work.

This work also considers another enclosure, in this case a lamp, which is composed as described in Section 3.1 by a tungsten filament inside a quartz glass envelope. In this enclosure, the filament exchanges heat, mostly in the form of radiation with the inner surface of the quartz envelope. At the same time, part of this radiation is also exchanged with the external glass surface due to the glass being a transparent medium; this is fundamental when defining the radiosity balance among the surfaces involved in the general enclosure.

To calculate the radiation energy of a gray surface, first the radiation energy for an equivalent black body is calculated using the Planck's Law (27); then, a correcting factor that is specific for each surface nature and temperature is applied to transform the black body radiation into a gray body radiation. Those correcting factors are discussed later in this work.

$$
E_{b}=\int_{0}^{\infty} \frac{C_{1}}{\lambda^{5} \cdot\left[e^{\left(\frac{C_{2}}{\lambda \cdot T}\right)}-1\right]} d \lambda
$$

with:

$$
\begin{gathered}
C_{1}=2 \cdot \pi \cdot h \cdot c_{0}^{2}=3.742 \times 10^{8}\left[\frac{\mathrm{W} \cdot \mu \mathrm{m}^{4}}{\mathrm{~m}^{2}}\right] \\
C_{2}=\frac{h \cdot c_{0}}{k_{b}}=1.439 \times 10^{4}[\mu \mathrm{m} \cdot \mathrm{K}]
\end{gathered}
$$

where:

- $\lambda$ : Wavelength, $\mu \mathrm{m}$.

- $T$ : Absolute temperature of the black body, $\mathrm{K}$.

- $\quad h$ : Universal Planck constant, $6.626 \times 10^{-34}[\mathrm{~J} \cdot \mathrm{s}]$.

- $\quad k_{b}$ : Boltzmann constant, $1.381 \times 10^{-23}[\mathrm{~J} / \mathrm{K}]$.

- $\quad c_{0}$ : Speed of light in vacuum, $2.998 \times 10^{8}[\mathrm{~m} / \mathrm{s}]$.

For this work, the radiation energy is focused on the infrared region of the spectrum, narrowing the calculation region between $\lambda_{1}$ and $\lambda_{2}(0.4 \mu \mathrm{m}$ and $20 \mu \mathrm{m}$, respectively); then, the total energy for a black body is obtained using (30) from Planck's Law (27). 


$$
E_{\lambda, b}=\int_{\lambda_{1}}^{\lambda_{2}} \frac{C_{1}}{\lambda^{5} \cdot\left[e^{\left(\frac{C_{2}}{\lambda \cdot T}\right)}-1\right]} d \lambda
$$

As the energy calculation depends of the wavelength and the integration must take place along a finite band of wavelengths, the numerical solution is achieved evaluating the first 10 terms of the infinite series (31), where $\sigma$ stands for the Stefan-Boltzmann constant, $5.670 \cdot 10^{-8}\left[\frac{\mathrm{W}}{\mathrm{m}^{2} \cdot \mathrm{K}^{4}}\right]$. By dividing the studied wavelength interval into 20 equally distributed evaluation domains, it is possible to obtain a good approximation while improving the calculation time in comparison with numerical integration routines [28,31].

$$
E_{b}(T)=\sigma \cdot T^{4}\left[\frac{15}{\pi^{4}}\left(\sum_{n=1}^{\infty} \frac{e^{-n \cdot \xi_{2}}}{n}\left(\xi_{2}^{3}+\frac{3 \xi_{2}^{2}}{n}+\frac{6 \xi_{2}}{n^{2}}+\frac{6}{n^{3}}\right)-\sum_{n=1}^{\infty} \frac{e^{-n \cdot \xi_{1}}}{n}\left(\xi_{1}^{3}+\frac{3 \xi_{1}^{2}}{n}+\frac{6 \xi_{1}}{n^{2}}+\frac{6}{n^{3}}\right)\right)\right]
$$

with:

$$
\begin{aligned}
& \xi_{2}=\frac{h \cdot c_{0}}{k_{b} \cdot \lambda_{2} \cdot T} \\
& \xi_{1}=\frac{h \cdot c_{0}}{k_{b} \cdot \lambda_{1} \cdot T}
\end{aligned}
$$

\subsubsection{Radiative Fluxes}

To define the radiative balance, an identification of the surfaces involved is presented in Figure 8 , as well as the radiosity, $J_{i}$, and irradiation, $G_{i}$, notations for each surface with their respective indices.

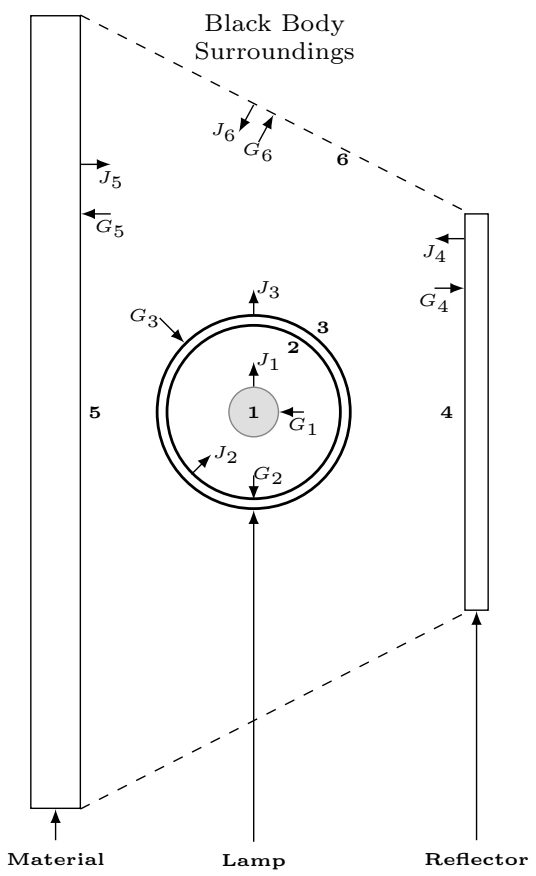

Figure 8. Surface identification. (1) Tungsten filament surface. (2) Internal quartz glass surface. (3) External quarts glass surface. (4) Reflector surface. (5) Material surface. (6) Equivalent surroundings surface. 
The boundary condition labeled as 6 is defined as a black body representing a surface that encloses the enclosure. This allows us to determine the net radiating heat transfer (34) using relation (35) for each surface.

$$
\begin{gathered}
q_{i}^{\prime \prime}=J_{i}-G_{i} \\
J_{\lambda, i}=r_{\lambda, i} \cdot G_{i}+\tau_{\lambda, i} \cdot G_{\lambda, i}+\varepsilon_{\lambda, i} \cdot \sigma \cdot T_{i}^{4}
\end{gathered}
$$

The first step is consider the radiosity for each surface, giving the set of relations (36) through (41):

$$
\begin{gathered}
J_{\lambda, 1}=r_{\lambda, 1} \cdot G_{\lambda, 1}+\varepsilon_{\lambda, 1} \cdot E_{\lambda, 1} \\
J_{\lambda, 2}=r_{\lambda, 2} \cdot G_{\lambda, 2}+\tau_{\lambda, 3} \cdot G_{\lambda, 3}+\varepsilon_{\lambda, 2} \cdot E_{\lambda, 2} \\
J_{\lambda, 3}=r_{\lambda, 3} \cdot G_{\lambda, 2}+\tau_{\lambda, 2} \cdot G_{\lambda, 2}+\varepsilon_{\lambda, 3} \cdot E_{\lambda, 3} \\
J_{\lambda, 4}=r_{\lambda, 4} \cdot G_{\lambda, 4}+\varepsilon_{\lambda, 4} \cdot E_{\lambda, 4} \\
J_{\lambda, 5}=r_{\lambda, 5} \cdot G_{\lambda, 5}+\varepsilon_{\lambda, 5} \cdot E_{\lambda, 5} \\
J_{\lambda, 6}=r_{\lambda, 6} \cdot G_{\lambda, 6}+\varepsilon_{\lambda, 6} \cdot E_{\lambda, 6}
\end{gathered}
$$

as suggested in [18,34]. In generic matrix form, for $n$ involved surfaces, the relation is given by (42):

$$
\left[J_{\lambda, j}\right]_{n \times 1}=[r]_{n \times n}\left[G_{\lambda, j}\right]_{n \times 1}+[\tau]_{n \times n}\left[G_{\lambda, j}\right]_{n \times 1}+[\varepsilon]_{n \times n}\left[E_{\lambda, j}\right]_{n \times 1}
$$

where relations (37) and (38), which are related to the quartz envelope, contemplate the transmission $\tau_{\lambda, i}$ between both the inner and outer surfaces due to the glass being a semitransparent medium. The term $r_{\lambda, i}$ refers to the reflectivity of the body and the term $\varepsilon_{\lambda, i}$ refers to the emissivity; all surfaces are considered diffuse gray bodies. Relation (41) refers to the surroundings considered as black bodies, acting as a heat sink as the temperature is known and kept constant over time. According to literature [18,28,29,35], it is defined $r_{\lambda, 6}=0$.

The second step is to consider the irradiation balance on the different surfaces by using (43):

$$
A_{i} \cdot G_{\lambda, i}=\sum_{j=1}^{n}\left[A_{j} \cdot J_{\lambda, j} \cdot F_{j-i}\right],
$$

where $F_{j-i}$ is the view factor from surface $j$ to surface $i$ and $A_{i}$ and $A_{j}$ are the areas of surfaces $i$ and $j$, respectively.

From the view factor reciprocity property (44), the expression (43) can be written as (45) or in its compact form (46).

$$
\begin{gathered}
A_{i} \cdot F_{i-j}=A_{j} \cdot F_{j-i} \\
A_{i} \cdot G_{\lambda, i}=A_{i} \cdot J_{\lambda, 1} \cdot F_{i-1}+A_{i} \cdot J_{\lambda, 2} \cdot F_{i-2}+A_{i} \cdot J_{\lambda, i} \cdot F_{i-i}+\cdots+A_{i} \cdot J_{\lambda, n} \cdot F_{i-n} \\
G_{\lambda, i}=\sum_{j=1}^{n} J_{\lambda, j} \cdot F_{i-j}
\end{gathered}
$$

In matrix form, for $n$ involved surfaces the relation can be written as (47):

$$
\left[G_{\lambda, i}\right]_{n \times 1}=[F]_{n \times n}\left[J_{\lambda, j}\right]_{n \times 1}
$$

In order to solve this equation system, Equations (42) and (47) are combined, leading to (48) and enabling the computation of the irradiation.

$$
\left[G_{\lambda, i}\right]_{n \times 1}=\left([I]_{n \times n}-[F]_{n \times n}\left([r]_{n \times n}+[\tau]_{n \times 1}\right)\right)^{-1}[F]_{n \times n}[\varepsilon]_{n \times 1}\left[E_{\lambda, i}\right]_{n \times 1}
$$

Then, the results obtained using (48) are used in (42) to calculate the radiosity $J_{\lambda, i}$. This allows the computation of the net radiative flux, leaving each involved surface per unit 
area defined as (34), which are the boundary conditions needed to solve the lamp (1), (4), and (5); the reflector (7); and the material (14) temperatures.

\subsubsection{View Factors}

The view factors used in (43) through (48) are taken from the literature [28-31,36], the view factor relations (49), and the reciprocity (44).

$$
\sum_{j=1}^{n} F_{i-j}=1
$$

As mentioned before, the lamp is modeled as a solid tungsten cylinder inside a quartz glass envelope (enclosure); thus, the view factor for infinitely long concentric cylinders can be expressed as (50), (51), and (52), whose indices refer to the notation shown in Figure 8.

$$
\begin{gathered}
F_{1-2}=1 \\
F_{2-1}=\frac{d_{c o i l}}{d_{l}} \\
F_{2-2}=1-F_{2-1}
\end{gathered}
$$

The view factor for an infinitely long cylinder to an infinitely long rectangle can be obtained using the scheme presented in Figure 9a, with the one presented in Figure $9 \mathrm{~b}$ being a particular case when $b_{1}=b / 2$.

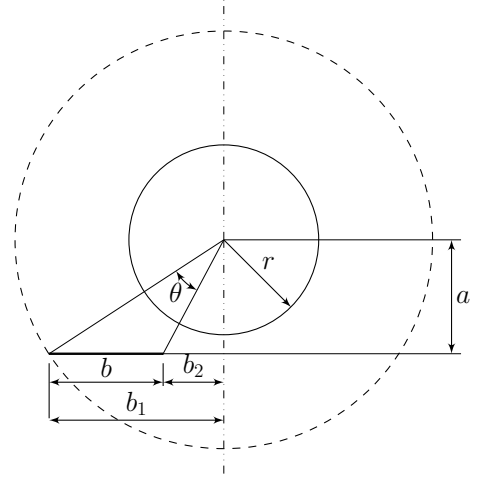

(a)

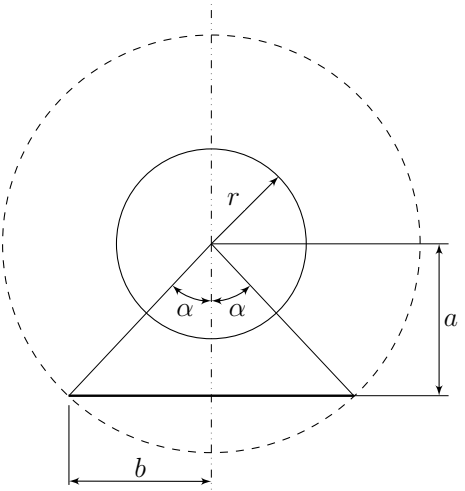

(b)

Figure 9. View factor between a cylindrical surface and a plane surface. (a) Rectangle not aligned with the cylinder vertical center line. (b) Rectangle symmetrically aligned with the cylinder vertical center line.

The relation used to calculate the different view factor values for the case between the lamp and the reflector and the lamp and each material cell are expressed in (53a) and (53b), where the subscript $c y l$. refers to the outer lamp surface labeled as " 3 " in Figure 8 , while subscript rect. refers to the reflector labeled as 4 and the material labeled as 5 in the same figure.

$$
\begin{gathered}
F_{\text {cyl.-rect. }}=\frac{1}{2 \cdot \pi}\left(\tan ^{-1} \frac{b_{1}}{a}-\tan ^{-1} \frac{b_{2}}{a}\right) \\
F_{\text {rect. }-c y l .}=\frac{r}{b}\left(\tan ^{-1} \frac{b_{1}}{a}-\tan ^{-1} \frac{b_{2}}{a}\right)
\end{gathered}
$$

The view factors between two planar surfaces, in the 2D case, can be expressed using Hottel's cross string method. Figure 10 shows the different components of this method. The values $L_{1}, L_{2}, L_{3}, L_{4}, L_{5}$, and $L_{6}$ are lengths, with $L_{1}$ and $L_{2}$ being the surfaces involved in the view factor and the remaining values distances between the edges of the surfaces-in this case, the cells of the finite volume method. 


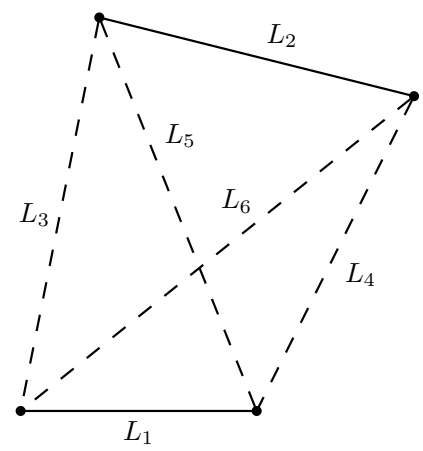

Figure 10. Two-dimensional planar geometry. Hottel's method.

The view factor obtained using the Hottel's method is expressed as (54) for the case $F_{L_{1}-L_{2}}$ and (55) for the case $F_{L_{2}-L_{1}}$.

$$
\begin{aligned}
& F_{1-2}=\frac{\left(L_{5}+L_{6}\right)-\left(L_{3}+L_{4}\right)}{2 \cdot L_{1}} \\
& F_{2-1}=\frac{\left(L_{5}+L_{6}\right)-\left(L_{3}+L_{4}\right)}{2 \cdot L_{2}}
\end{aligned}
$$

\section{Properties}

The properties of the elements involved in the heat exchange process are temperature-dependant and can be classified as thermal or optical properties, directly affecting the heat flux distribution model.

\subsection{Thermal Properties}

In Equations (1), (4), and (5), the specific heat of the tungsten, $c p_{w}\left(T_{f}\right)$, as well as the quartz, $c p_{q}\left(T_{q}\right)$, are needed. These data were collected from the literature $[18,29,37]$ and summarized in (56) and (57) for the tungsten with a temperature range of $298 \mathrm{~K}<T<$ $1900 \mathrm{~K}$ and $1900 \mathrm{~K}<T<3680 \mathrm{~K}$, respectively, and for the quartz (58) with a temperature range of $298 \mathrm{~K}<\mathrm{T}<2000 \mathrm{~K}[29,38,39]$.

$$
c p_{w}\left(T_{f}\right)=\frac{\left[23.9593+2.63968 \frac{T_{f}}{10}+1.25775\left(\frac{T_{f}}{10}\right)^{2}-0.25364\left(\frac{T_{f}}{10}\right)^{3}-\frac{0.048407}{\left(\frac{T_{f}}{10}\right)^{2}}\right]}{183.84 \times 10^{-3}}
$$

Additionally, the tungsten resistivity and thermal conductivity of the neon, which are both temperature-dependant, are required. From [18], the data for the tungsten resistivity are given by (59) for a temperature range $300 \mathrm{~K}<T<3655 \mathrm{~K}$, while the conductivity for neon gas is given by (60) for a temperature range of $100 \mathrm{~K}<T<2500 \mathrm{~K}$.

$$
\begin{gathered}
r_{w}\left(T_{f}\right)=-5.0134 \times 10^{-9}+7.3070759 \times 10^{-11} \cdot T_{f}^{1.1796583} \\
k_{N e}\left(T_{N e}\right)=-3.6018021 \times 10^{-3}+1.4290623 \times 10^{-3} \cdot T_{N e}^{0.63362378}
\end{gathered}
$$


Equation (7) requires the specific heat of the reflector, $c p_{r}\left(T_{r}\right)$, whose expression is presented in (61) for a temperature range of $298 \mathrm{~K}<T<933 \mathrm{~K}[37,40,41]$. Its thermal conductivity, $k_{r}\left(T_{r}\right)$, is expressed in (62) for a temperature range of $250 \mathrm{~K}<T<800 \mathrm{~K}$ [42].

$$
\begin{gathered}
c p_{r}\left(T_{r}\right)=\frac{4.186 \cdot\left(4.94+2.96 \times 10^{-3} \cdot T_{r}\right)}{26.98154} \\
k_{r}\left(T_{r}\right)=186.0219+0.327088 \cdot T_{r}-6.069629 \times 10^{-4} \cdot T_{r}^{2}+3.101227 \times 10^{-7} \cdot T_{r}^{3}
\end{gathered}
$$

\subsection{Optical Properties}

The optical properties needed by the system of Equation (42) for each surface type are wavelength-dependant. For general surfaces, the relation among its optical properties is expressed by (63); for the case of opaque surfaces which have no transmissivity $\tau=0$, the relation among its optical properties is expressed in (64) [27,41].

$$
\begin{aligned}
& r+\alpha+\tau=1 \\
& \varepsilon \cong \alpha=1-r
\end{aligned}
$$

To estimate the optical properties of the opaque surfaces, the Maxwell electromagnetic wave theory gives the emissivity value (65), which, when used in (64), leads to the reflectivity:

$$
\varepsilon_{n, \lambda}=\frac{4 \cdot n}{n^{2}+k^{2}+1+2 \cdot n}
$$

where $n$ and $k$ are given by Equations (66) and (67), respectively:

$$
\begin{aligned}
& n^{2}=\frac{1}{2}\left(\sqrt{\left(\frac{\epsilon}{\epsilon_{0}}\right)^{2}+\left(\frac{\lambda}{r_{i} \cdot 2 \cdot c_{0} \cdot \epsilon_{0}}\right)^{2}}+\frac{\epsilon}{\epsilon_{0}}\right) \\
& k^{2}=\frac{1}{2}\left(\sqrt{\left(\frac{\epsilon}{\epsilon_{0}}\right)^{2}+\left(\frac{\lambda}{r_{i} \cdot 2 \cdot c_{0} \cdot \epsilon_{0}}\right)^{2}}-\frac{\epsilon}{\epsilon_{0}}\right)
\end{aligned}
$$

with:

- $\quad \frac{\epsilon}{\epsilon_{0}}$ : relative material $i$ permitivity.

- $\epsilon_{0}$ : vacuum permitivity $\left[\mathrm{F} \cdot \mathrm{m}^{-1}\right]$.

- $\quad r_{i}$ : resistivity of element $i,[\Omega \cdot \mathrm{m}]$. For a filament the resistivity is given by (59); for a reflector the resistivity is given by $(68)[42,43]$.

$$
r_{r}=-1.1961 \times 10^{-8}+1.5272 \times 10^{-10} \cdot T_{r}-9.4257 \times 10^{-14} \cdot T_{r}^{2}+7.2288 \times 10^{-17} \cdot T_{r}^{3}
$$

For the tungsten filament, the value for the relative permitivity is $\epsilon / \epsilon_{0}=1.000068$ and for the reflector $\epsilon / \epsilon_{0}=1.00000065$ [44].

The optical properties of the quartz glass envelope are gathered from specialized literature on the study of infrared dryers and from papers specializing in the study of material optical properties [34,45].

The emissivity values used in (41) is $\varepsilon_{\lambda}=1$ for the surroundings are considered as black bodies.

\subsection{Convection Coefficients}

For the convection parameters needed for solving (5), (7), and (14), empirical correlations are used to estimate $h_{1}, h_{2 r}, h_{2 q}, h_{2 m}$, and $h_{3}$ [27]. These correlations estimate an average convection coefficient for the air $\overline{h_{i}}$ by calculating an average Nusselt number $N u$. The 
properties for the air at atmospheric pressure are computed at $T_{\text {film }}(69)$ according to the information presented in the literature [27].

$$
T_{f i l m}=\frac{T_{i}+T_{\infty}}{2}
$$

To estimate $h_{1}$, the set of correlations (70), (71), and (72) for perpendicular air flow were used, where the value $U$ of the movement of the machine head is used to calculate the Reynolds number.

$$
\begin{gathered}
R e_{r 1}=\frac{U \cdot W_{r}}{v\left(T_{f i l m}\right)} \\
\overline{N u_{r 1}}=0.228 \cdot R e_{W_{r}}^{0.731} \cdot P r_{\text {air }}\left(T_{\text {film }}\right)^{1 / 3} \\
\overline{h_{1}}=\frac{\overline{N u_{r 1}} \cdot k_{\text {air }}\left(T_{\text {film }}\right)}{W_{r}}
\end{gathered}
$$

For the left-hand side of the reflector $h_{2 r}$, the correlations for a vertical plane with free convection (73), (74), and (75) were used:

$$
\begin{aligned}
& \overline{N u_{r 2}}=\left\{0.825+\frac{0.387 \cdot R a_{r 2}^{1 / 6}}{\left[1+\left(0.492 / \operatorname{Pr}_{\text {air }}\left(T_{\text {film }}\right)\right)^{9 / 16}\right]^{8 / 27}}\right\}^{2} \\
& R a_{r 2}=\frac{g \cdot\left(1 / T_{f i l m}\right) \cdot\left(T_{r}-T_{\infty}\right) \cdot W_{r}^{3}}{v\left(T_{f i l m}\right) \cdot \alpha\left(T_{f i l m}\right)} \\
& \overline{h_{2 r}}=\frac{\overline{N u_{r 2}} \cdot k_{a i r}\left(T_{\text {film }}\right)}{W_{r}}
\end{aligned}
$$

where $g=9.807 \mathrm{~m} / \mathrm{s}^{2}$.

For the lamp $h_{2 q}$, the correlations for a cylinder with free convection were used (76): (77) and (78). The position of the reflector relative to the lamp blocks the air flow due to the machine head assembly movement.

$$
\begin{aligned}
& \overline{N u_{q}}=\left\{0.60+\frac{0.387 \cdot R a_{q}^{1 / 6}}{\left[1+\left(0.559 / P r_{\text {air }}\left(T_{\text {film }}\right)\right)^{9 / 16}\right]^{8 / 27}}\right\}^{2} \\
& R a_{q}=\frac{g \cdot\left(1 / T_{f i l m}\right) \cdot\left(T_{q}-T_{\infty}\right) \cdot W_{r}^{3}}{\nu\left(T_{f i l m}\right) \cdot \alpha\left(T_{f i l m}\right)} \\
& \overline{h_{2 q}}=\frac{\overline{N u_{q}} \cdot k_{\text {air }}\left(T_{\text {film }}\right)}{d_{L}}
\end{aligned}
$$


For the case of $h_{2 m}$ and $h_{3}$, the same correlations are used-(79), (80), and (81) — which consider an external air flow of velocity $U$ parallel to the material surface due to the material motion relative to the air, which is assumed be in a quiescent state.

$$
\begin{gathered}
R e_{m}=\frac{U \cdot W_{m}}{v\left(T_{\text {film }}\right)} \\
\overline{N u_{m}}=\frac{0.3387 \cdot R e_{m}^{1 / 2} \cdot \operatorname{Pr}_{\text {air }}\left(T_{\text {film }}\right)^{1 / 3}}{\left[1+\left(0.0468 / P r_{\text {air }}\left(T_{\text {film }}\right)\right)^{2 / 3}\right]^{1 / 4}} \\
\overline{h_{m}}=\frac{\overline{N u_{m}} \cdot k_{\text {air }}\left(T_{\text {film }}\right)}{W_{m}}
\end{gathered}
$$

\section{Materials and Methods}

\subsection{Material Description}

As a case of study for the ATL process, the employed material is a carbon fiber-reinforced Polyamide 6 tape from Toray with the commercial denomination Cetex TC $910^{\circledR}$. This has a $50 \mathrm{~mm}$ width, $0.16 \mathrm{~mm}$ thickness, and a fiber content of $60 \%$ [46].

\subsubsection{Thermal Properties}

Equation (13) requires the material heat capacity as a function of temperature, $c p_{m}\left(T_{m}\right)$. An experimental procedure was performed according to ASTM E 1269-9901 [47] for material samples, giving the results shown in Figure 11 for a temperature range of $300 \mathrm{~K}<T<508 \mathrm{~K}$.

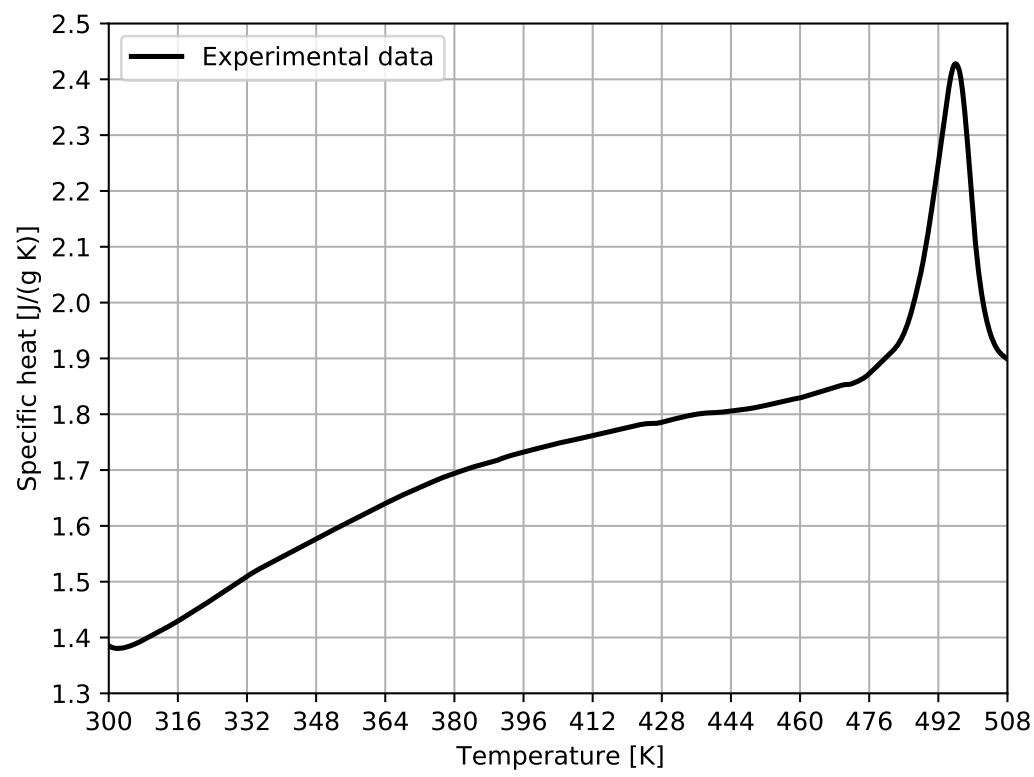

Figure 11. Specific heat for the composite material as a function of temperature.

Another property required in (13) is the material conductivity, $k_{m}\left(T_{m}\right)$. An in house procedure was used to determine this property as a function of temperature based on theoretical and practical works by [48-51]. The resulting data are presented in Figure 12 for a temperature range of $300 \mathrm{~K}<T<503 \mathrm{~K}$. 


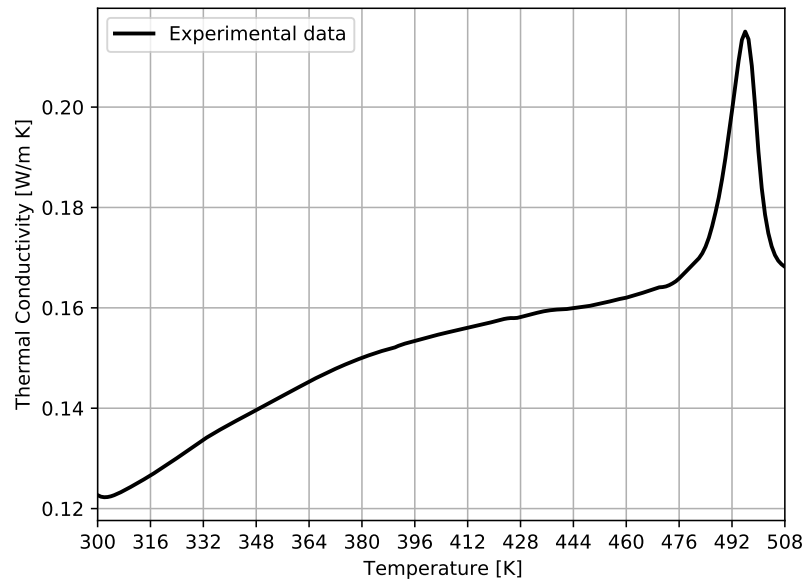

Figure 12. Thermal conductivity for the composite material as a function of temperature.

\subsubsection{Optical Properties}

In order to obtain the emissivity, $\varepsilon_{m}\left(T_{m}\right)$, and reflectivity, $r_{m}\left(T_{m}\right)$ of the composite material as a function of temperature, an in house test was designed based on the procedure indicated by pirometer manufacturers to determine the emissivity of the object being measured [52]. The results are presented in Figure 13.

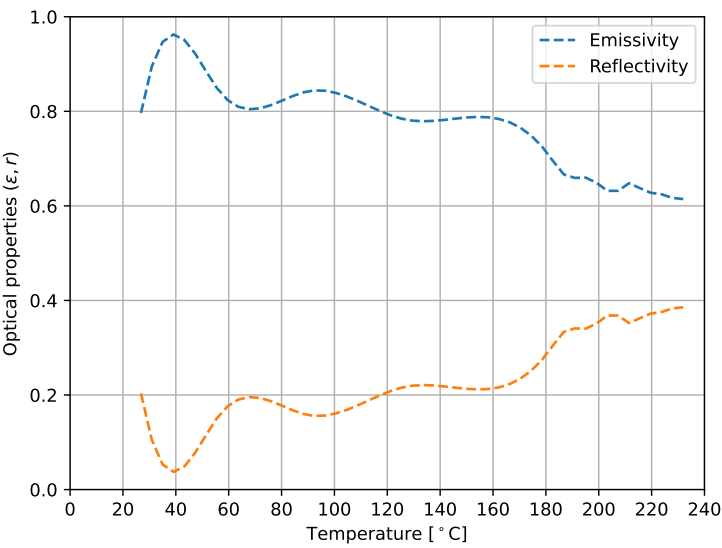

Figure 13. Emissivity and reflectivity as functions of temperature for the composite material obtained by an in-house test.

\subsection{Methods}

\subsubsection{Time Integration Scheme}

The mathematical model involves a set of non-linear ordinary differential equations (ODE) for the temperature time derivative of the different components-namelym the tungsten filament (1), the quartz lamp (5), the reflector cell temperature (8), and the material cell temperature (14). To solve this ODE system, the initial condition is set to be the ambient temperature for all the components. The implicit solver Radau IIA is selected from the Scientific Python library [53] to avoid time-step limitations due to equation stiffness.

The ODE equation system is structured in a array-like way as an explicit function of the given trial temperature suitable for the external solver. To evaluate the ODE system, the following steps are performed:

Step 1. For the given trial temperature.

Step 2. Evaluate all material properties at the trial temperature.

Step 3. Solve the radiation heat flux system for the trial temperature. 
Step 4. Evaluate the ODE system array with the temperature derivatives.

The model solver consists on two parts, with the first one being the calculation of the net radiation flux using the current temperature as a reference to determine all the properties required. The second part consists of implementing the result of the net radiation flux as an input to predict the process component temperature at the next time step. Finally, the new temperatures are used to calculate a new net heat flux and then the cycle repeats until the defined stop time.

The relative error tolerance for the solver is set to $10^{-4}$ and the absolute error tolerance to $10^{-6}$.

\subsubsection{Convergence Analysis}

A convergence analysis is performed to define a proper cell size for the material simulation in order to lower the required computational resource consumption using the lowest mesh size. Mesh sizes from 11 cells up to 239 cells were tested for the material. The mesh for the reflector was defined using the same cell size used for the material, regardless of the amount of cells, in order to preserve the stability during computation. Taking into account the temperature percentage variation using three selected points as a reference-namely, the first cell at which the material has its first interaction with the heat exchange process, the middle cell along the length of the material, and the last cell of the material-the mesh size is selected based on the lowest number of cells which gives a temperature variation under $0.5 \%$ with respect to the mesh size of 239 cells. The number of cells defined using odd values is intended to guarantee a central cell along the mesh at the same position, regardless of the mesh size.

\subsubsection{Measures and Instrumentation}

In order to measure the process parameters and the variables needed to feed the mathematical model, two types of data acquisition cards from National Instruments were used-namely, an NI 9234 for voltage measurements and an NI 9211 for temperature measurements. The NI 9234 data acquisition card allows high sampling rates and is adequate for measuring the $50 \mathrm{~Hz}$ frequency mains voltage that feeds the heating element.

To compute the electrical power delivered to the heating element, the applied voltage and the current consumption must be measured. A voltage transformer is used to step down the mains voltage sine wave to a safe range for the data acquisition card, as well as to provide galvanic isolation. For the current, a non-invasive current transformer is placed around one of the lines that powers the heating element; the output of this transformer is a voltage signal that is read by the same data acquisition card that reads the transformed mains voltage signal. The measurement strategy used for the voltage and current is presented in Figure 14.

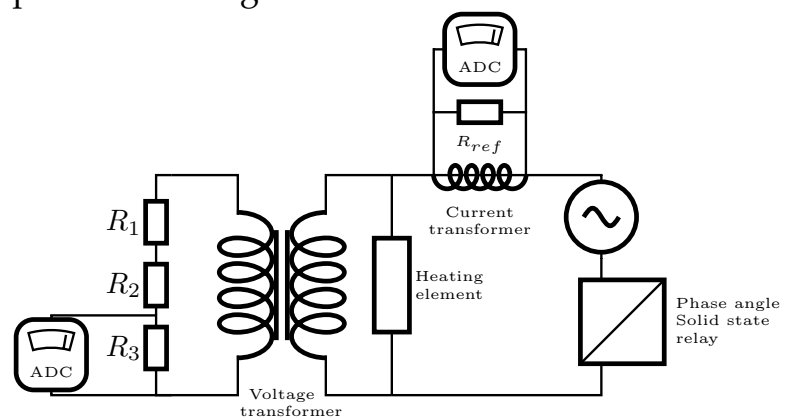

Figure 14. Voltage and current measurement strategy for electrical power consumption calculation.

To measure the temperatures involved, a set of thermocuples is placed at the following locations: the compaction roll fluid inlet and outlet, and on the top surface of the mold. The composite material temperature is measured using a pyrometer PyroNFC K from CALEX facing the composite material at a point $h$ above the center line of the compaction 
roll, as presented in Figure 15. The output of the pyrometer is a thermocouple-like signal that can be read by the same data acquisition card, NI 9211, as the other thermocouples.

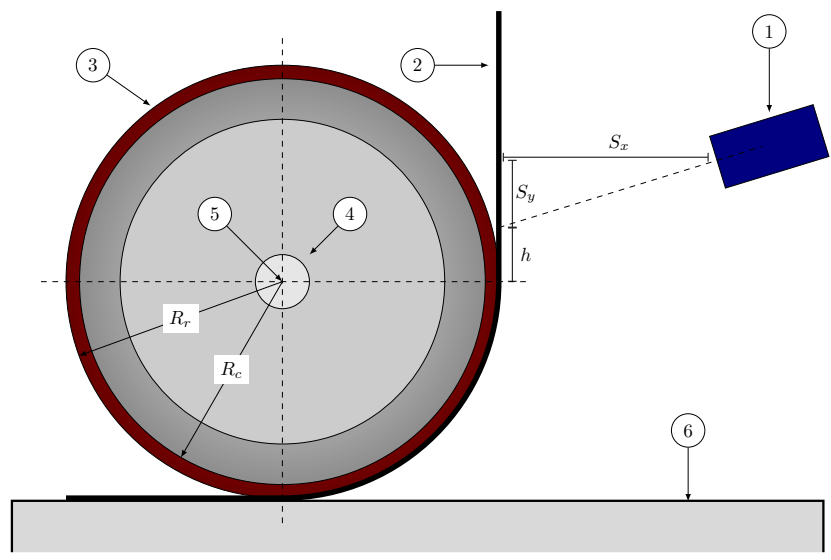

Figure 15. Composite material temperature measurement scheme. (1) Pyrometer PyroNFC-K. (2) Incoming composite material. (3) Compaction roll. (4) Compaction roll axis; fluid inlet/outlet ports. (5) Inlet fluid temperature sensor; outlet temperature sensor located at the other end of the axis. (6) Mold temperature sensor.

The last parameter to measure is the process speed; this value is obtained directly as a voltage from the analogue output of the servo motor driver OMROM R88D-KN08H-ECT and is read by the NI 9234 data acquisition card.

\subsubsection{Model Validation}

The experimental validation was performed in two parts. The first part consists of validating the temperature dynamics of the material at the measuring point, as shown in Figure 15, using a constant set of parameters-namely: process speed, compaction roll temperature, and mold temperature - and imposing changes in the voltage applied to the heating element. This voltage variation is conducted using a solid state relay that takes advantage of the phase angle strategy to reduce the delivered root mean square voltage and hence the electrical power delivered to the heating element.

The compaction roll temperature and the mold temperature are kept constant because any change to their respective reference generates a slow response in comparison with any change in reference for the voltage delivered to the heating element. The process speed is kept constant throughout the experiment because the driver controlling the servo motor only has signal outputs to monitor its value and any change will likely stop the process and change it manually. In order to see the influence of the speed upon the process, two sets of tests were carried out with different speed values, as presented in Table 2.

Table 2. Values for the process parameters.

\begin{tabular}{ccc}
\hline Parameter & Set $\mathbf{1}$ & Set $\mathbf{2}$ \\
\hline Compaction roll temperature & $55{ }^{\circ} \mathrm{C}$ & $55{ }^{\circ} \mathrm{C}$ \\
Mold temperature & $22{ }^{\circ} \mathrm{C}$ & $22{ }^{\circ} \mathrm{C}$ \\
Process speed & $5 \mathrm{~mm} / \mathrm{s}$ & $15 \mathrm{~mm} / \mathrm{s}$ \\
\hline
\end{tabular}

To understand the machine parameters' influence on the operation of the ATL head, regarding the consolidation temperature of the material tape at the nip point, the proposed test cases presented in Table 3 will be simulated. 
Table 3. Values for the process simulation.

\begin{tabular}{ccc}
\hline Simulation & Parameters & Values \\
\hline & Compaction roll Temperature & $55^{\circ} \mathrm{C}$ \\
Mold Temperature & $2{ }^{\circ} \mathrm{C}$ \\
& Speed & $5 \mathrm{~mm} / \mathrm{s}$ \\
& Voltage & $100 \mathrm{~V}$ \\
& Voltage & $150 \mathrm{~V}$ \\
& Voltage & $200 \mathrm{~V}$ \\
\hline & Compaction roll Temperature & $55^{\circ} \mathrm{C}$ \\
Mold Temperature & $22^{\circ} \mathrm{C}$ \\
& Voltage & $150 \mathrm{~V}$ \\
& Speed & $5 \mathrm{~mm} / \mathrm{s}$ \\
& Speed & $10 \mathrm{~mm} / \mathrm{s}$ \\
& Speed & $15 \mathrm{~mm} / \mathrm{s}$ \\
\hline
\end{tabular}

\section{Results}

\subsection{Mesh Convergence}

The results obtained for the convergence analysis are shown in Figure 16, for a speed value of $5 \mathrm{~mm} / \mathrm{s}$ in Figure 16a, and for a speed value of $15 \mathrm{~mm} / \mathrm{s}$ in Figure 16b, both with a simulation time of $30 \mathrm{~s}$ and the same process conditions of initial temperature and electrical power delivered to the heating element, as well as compaction roll, mold, and ambient temperature.

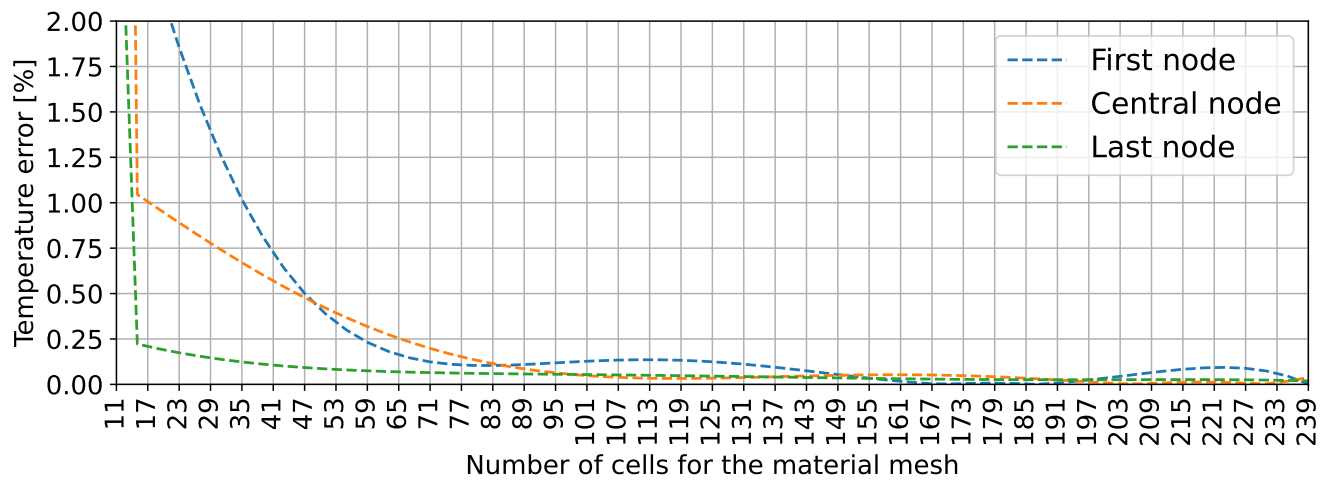

(a)

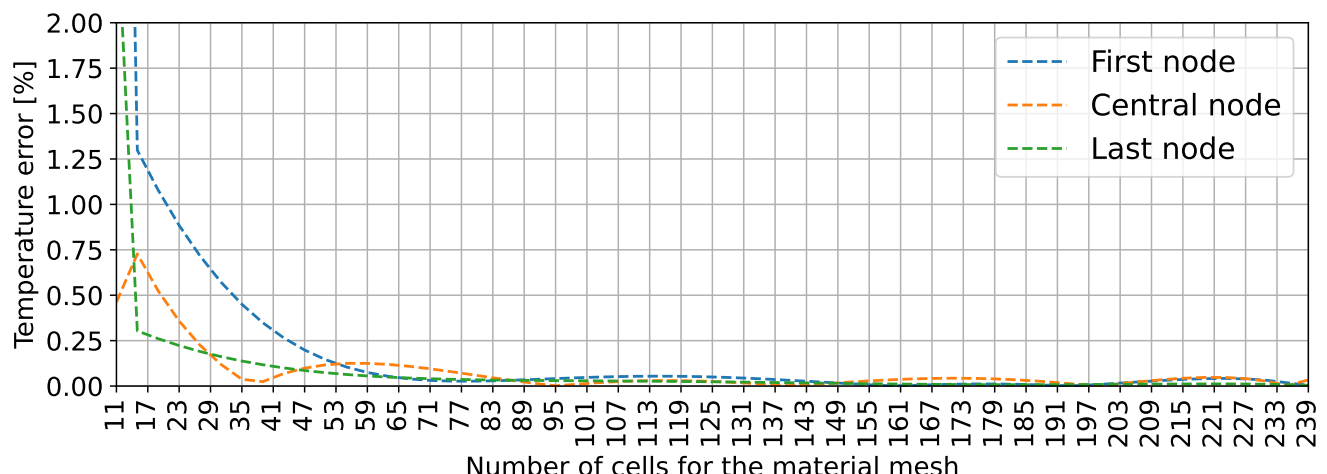

(b)

Figure 16. Temperature error as a function of the mesh size for the material. (a) speed value $5 \mathrm{~mm} / \mathrm{s}$. (b) speed value $15 \mathrm{~mm} / \mathrm{s}$. 
The data presented in Figure 16a show that, for a process speed of $5 \mathrm{~mm} / \mathrm{s}$, the material temperature value, at the selected locations, has a tendency to stabilize with a relative error below $0.5 \%$ for mesh sizes above 47 cells, and for the case of a process speed of $15 \mathrm{~mm} / \mathrm{s}$, the error below $0.5 \%$ is achieved with a mesh size above 35 cells. From this results, the selected mesh size is 51 cells, corresponding to the scenario presented in Figure 16a, with a cell size of $\Delta y=2.87 \mathrm{~mm}$.

The reflector cell size is fixed to have the same size as the material, although the reflector mesh size should have less influence.

\subsection{Model Validation}

In order to compare the dynamic response of the ATL machine with the predicted response of the proposed numerical model, different tests which parameters were defined according to the values presented in Table 2 as Set 1 and Set 2, were performed with multiple changes in the voltage supplied to the heating element. The results for the parameters Set 1 are presented in Figures 17 and 18, and for the Set 2 in Figures 19 and 20. This was carried out to simulate a possible control action and to analyze the transient response of the machine and the material.

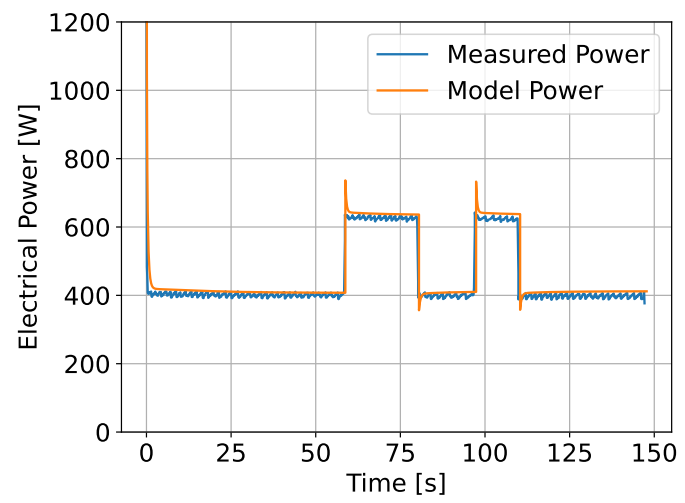

(a)

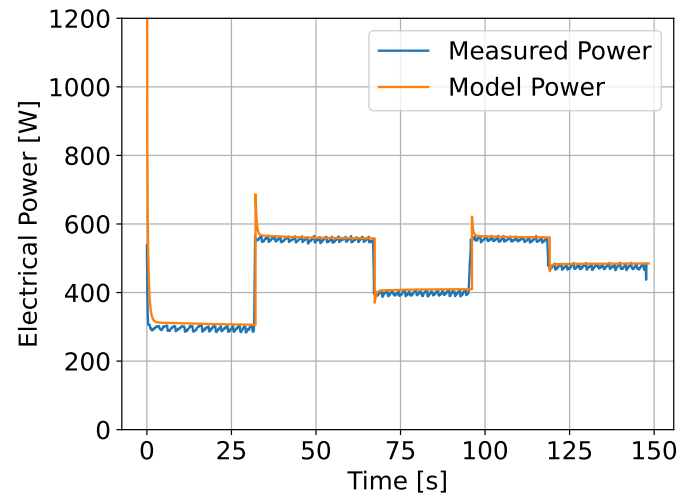

(c)

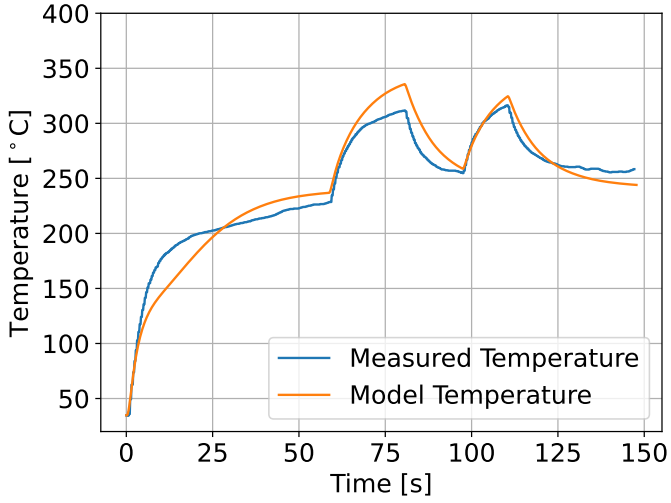

(b)

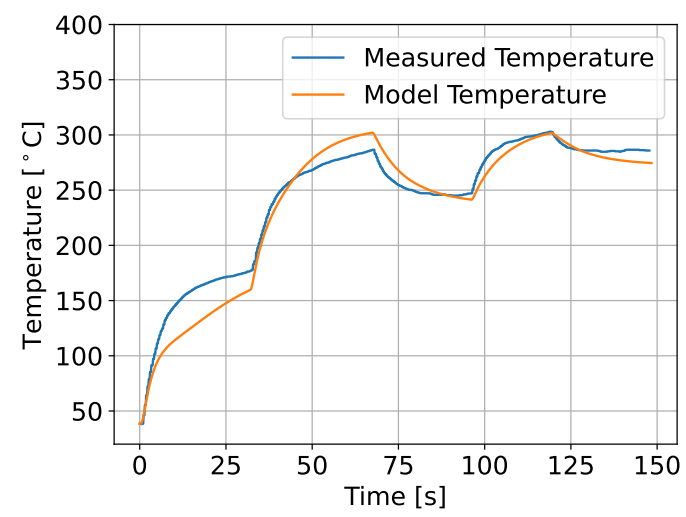

(d)

Figure 17. Results of Power consumption and temperature variation at the measuring point according to parameter set 1 from Table 2. (a) test 1, electrical power. (b) test 1, composite temperature response. (c) test 2, electrical power. (d) test 2, composite temperature response.

First, the predicted power consumption agrees with the experimental measured response, as shown in Figure 17a,c. This means that the proposed model is capable of predicting the overall energy flow of the system, which is a desirable result because it is based on energy conservation laws.

Comparing the measured temperature with the predicted temperature at the corresponding "machine measurement point", it is verified that the proposed model can 
predict the heating and cooling dynamics of the system, as shown in Figure $17 \mathrm{~b}, \mathrm{~d}$, according to the process speed value, compaction roll temperature, and mold temperature presented in Table 2 as Set 1.

The prediction of the material temperature was adjusted by defining a compensation factor for the convection coefficient of the heating element of 5.5, correlation (78), and a compensation factor of 2.5 for the convection coefficient of the material, correlation (81), in order to compensate the correlation approximations related to geometry and relative movement.

Additionally, the corresponding measurements for the compaction roll temperatures, mold temperature, and process speed for test set 1 are shown in Figure 18a,b.

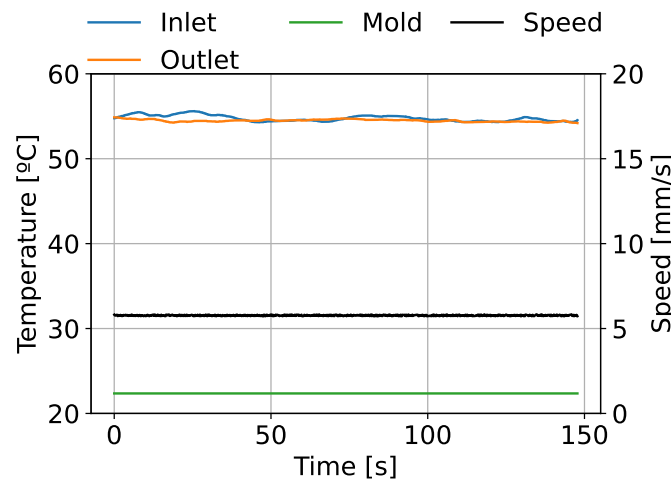

(a)

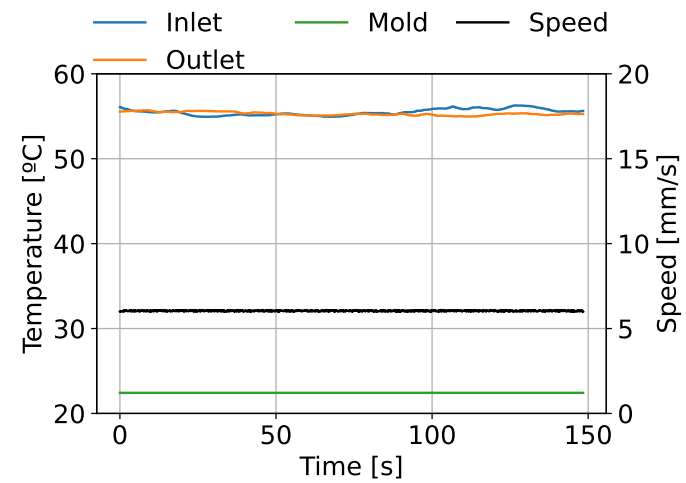

(b)

Figure 18. Inlet and outlet compaction roll temperatures and speed measurements for two test runs, Set 1 from Table 2 (a) first test, refering to Figure 17a,b. (b) second test, refering to Figure 17c,d.

The test and simulation results for the process parameters presented in Table 2 as Set 2 are presented in Figure 19, showing the predicted and measured power consumption for the heating element, Figure 19a,c, and predicted and measured temperature for the material at the measuring point, Figure 19b,d.

The model used to predict the composite material temperature at the machine measuring point shown in Figure 19b,d includes the same compensation factors in the convection coefficient for the heating element as well as in the material convection coefficient, showing an acceptable geometrical and relative movement compensation for those values.

The corresponding measurements for the compaction roll temperature, mold temperature, and process speed are shown in Figure 20.

As shown in Figures $17 \mathrm{~b}, \mathrm{~d}$ and $19 \mathrm{~b}, \mathrm{~d}$, the model is capable of predicting the temperature of the material for values above $150{ }^{\circ} \mathrm{C}(423.15 \mathrm{~K})$.

Comparing the measured temperatures at the same machine measuring point for both process speeds, it is noticed that when defining a machine speed of $15 \mathrm{~mm} / \mathrm{s}$, temperatures at this point are lower than the temperatures at the same point when tests are performed with a machine speed of $5 \mathrm{~mm} / \mathrm{s}$, showing the influence of the transport phenomena on the temperature evolution over time.

It can be seen that the compaction roll inlet and outlet temperatures are similar at both tests; this fact, added to an internal fluid flow through the compaction roll of $40 \mathrm{~L} / \mathrm{min}$ produced by a temperature control unit Tool-Temp 137BP, indicates that the internal flow is sufficient to guarantee a constant temperature along the compaction roll, validating the proposed model assumption of constant temperature given in Section 3.4. 


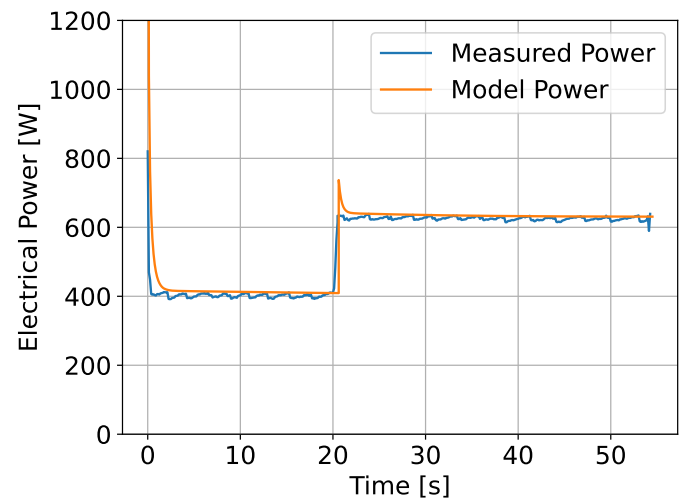

(a)

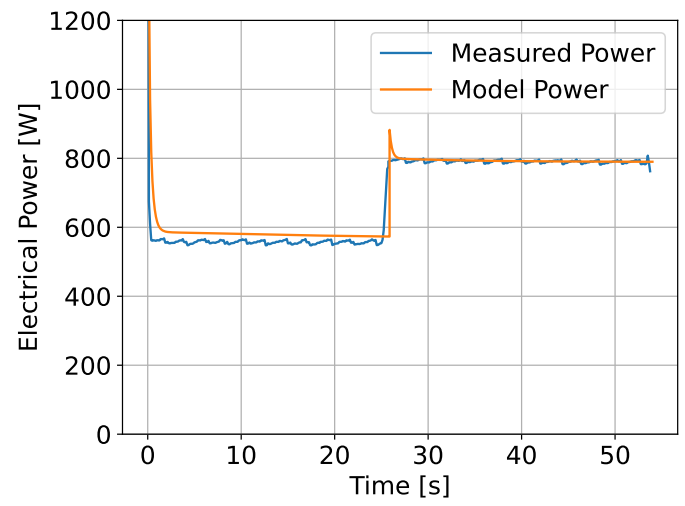

(c)

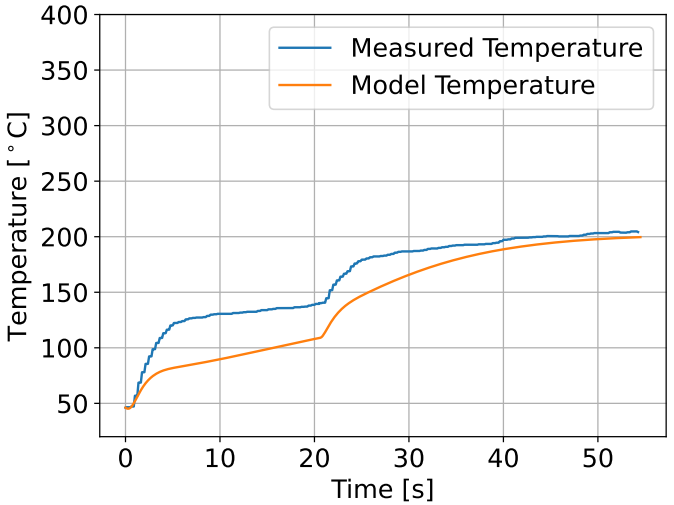

(b)

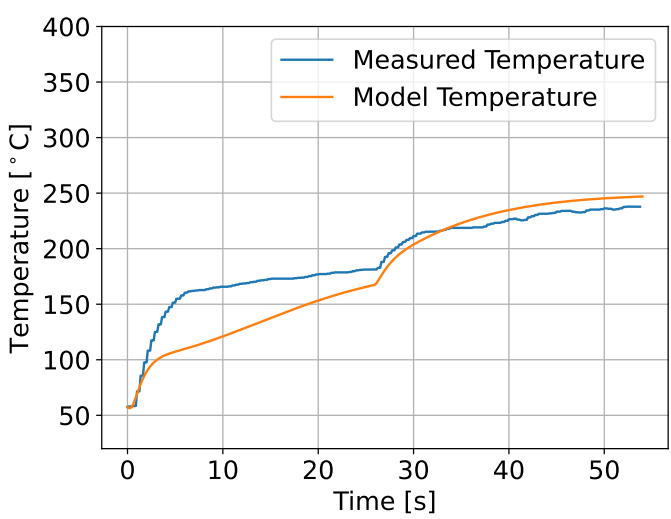

(d)

Figure 19. Results of power consumption and temperature variation at the measuring point according to parameter set 2 from Table 2. (a) Test 1, electrical power. (b) Test 1, composite temperature response. (c) Test 2, electrical power. (d) Test 2, composite temperature response.

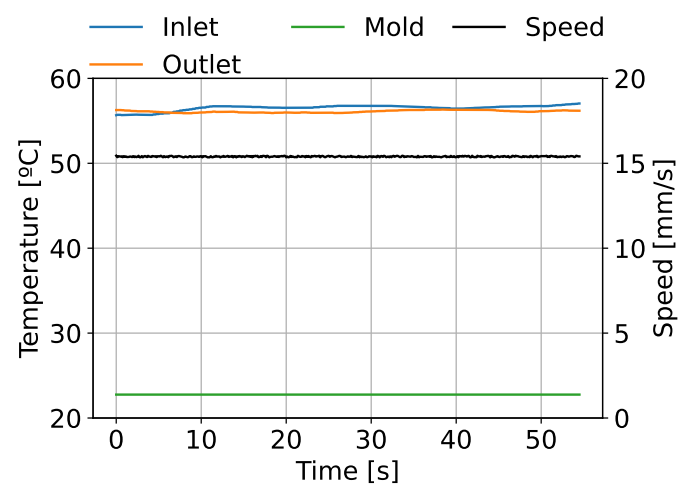

(a)

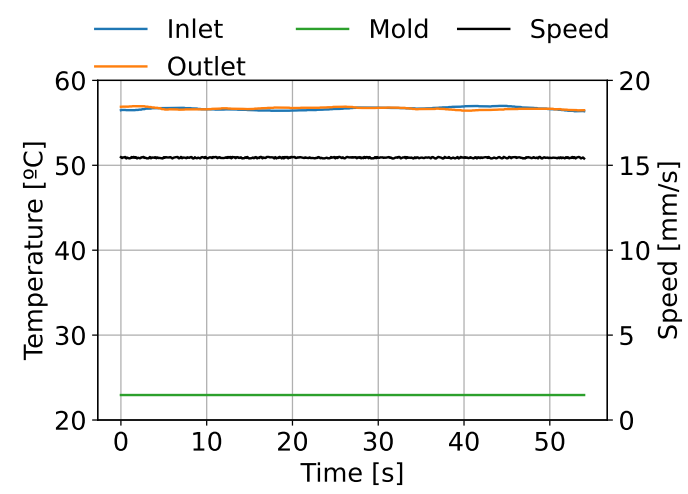

(b)

Figure 20. Inlet and outlet compaction roll temperatures and speed measurements for two test runs, Set 2 from Table 2. (a) First test, referring to Figure 19a,b. (b) Second test, referring to Figure 19c,d.

Figure 21 presents the prediction of the nip Ppint temperature, related to the measured tests presented in Figure 17b,d. A delay between the nip point temperature change and the predicted temperature at the measured point can be noticed in Figure 15 when simulating the change in voltage of the heating element by a control system while the process speed remains constant. 


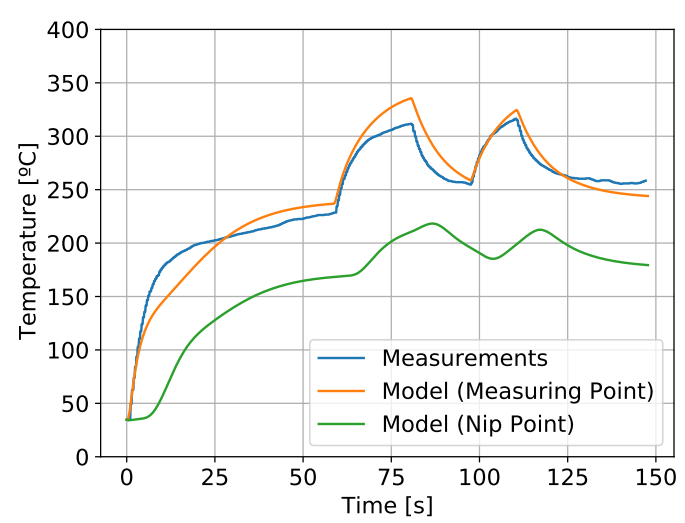

(a)

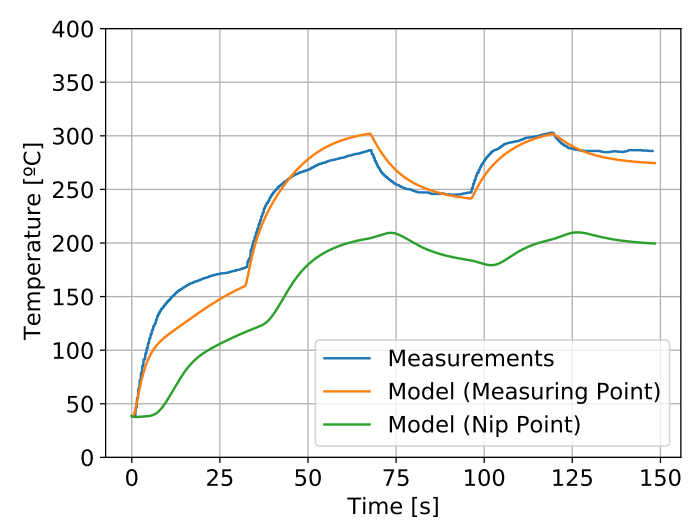

(b)

Figure 21. Temperature at measuring point, predicted at measuring point, and predicted at nip point. (a) First measured test. (b) Second measured test

This result is expected and is related to the transport phenomena due to the feed speed and the heat conduction to the roll.

\section{Sensitivity Analysis}

The results obtained for the simulations described in Table 3 are presented in Figure 22 for the simulation in which the speed of the process is kept constant (Simulation 1) and in Figure 23 for the simulation in which the voltage applied to the heating element is kept constant (Simulation 2).

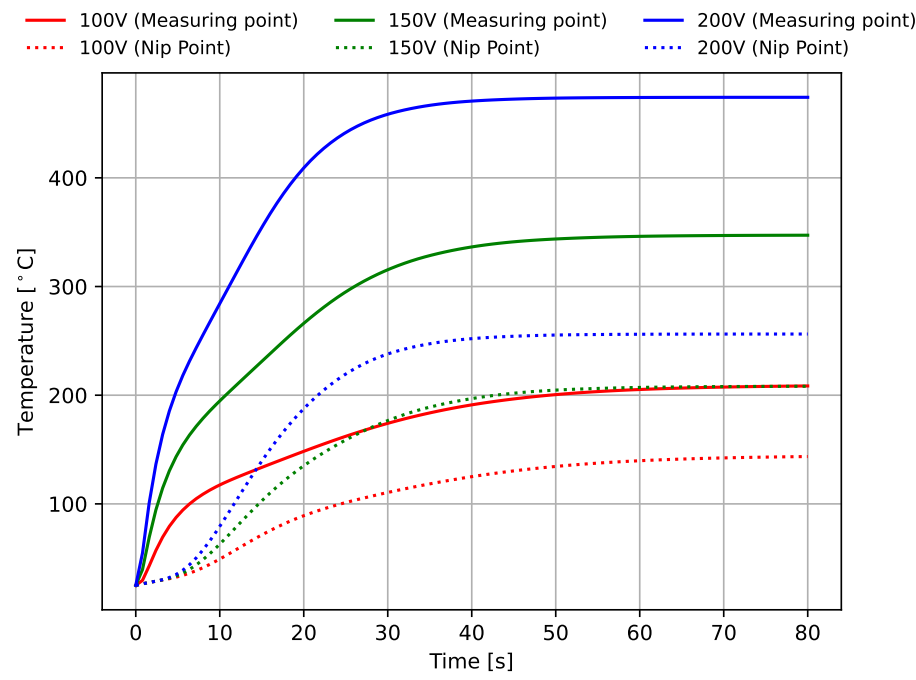

Figure 22. Results obtained for the simulations according to the first simulation proposed in Table 3.

For the case presented in Figure 22, the temperature at the nip point also presents a delay with respect to the measuring point as expected. This is controlled by ambient losses and the heat transferred to the roll. Figure 23 shows that the process speed has a relevant influence on the nip point temperature as its value increases; this effect can be noticed for the simulated speed of $10 \mathrm{~mm} / \mathrm{s}$. After the nip point temperature starts to rise, it almost matches the temperature of the measuring point, and for the case of a speed of $15 \mathrm{~mm} / \mathrm{s}$ the temperature experiences a start delay and rapidly reaches higher values with respect to the measuring point. This behaviour demonstrates the high sensitivity of the system to the feed speed, meaning that the transport phenomena dominates over the conduction and convection losses. 


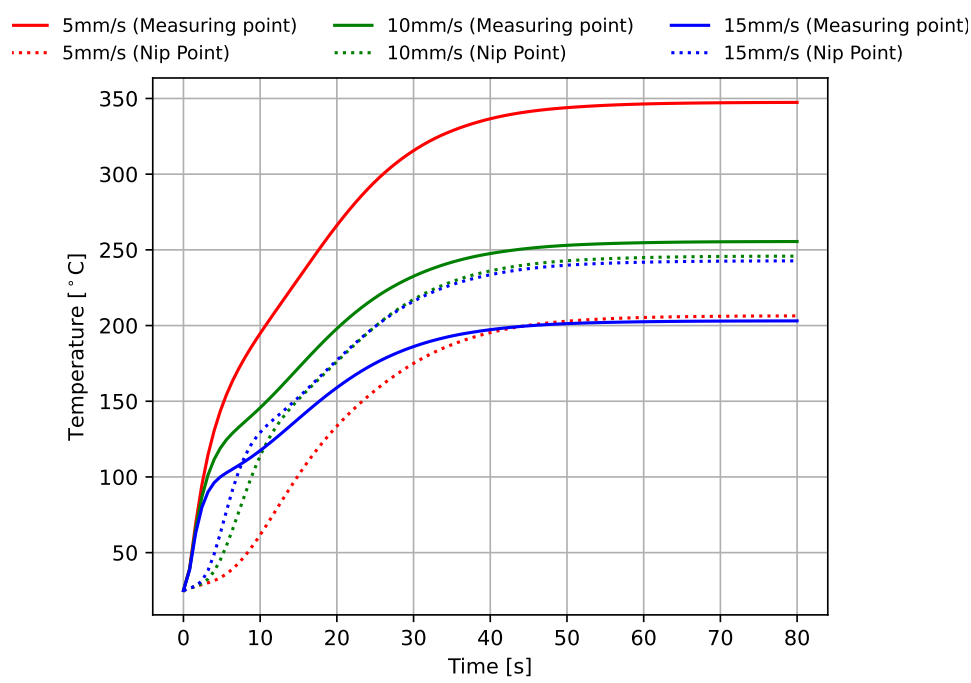

Figure 23. Results obtained for the simulations according to the second simulation proposed in Table 3.

\section{Conclusions}

The energy balance model proposed for the heating element is able to replicate the dynamics of its electrical energy consumption, taking into account its components' properties and geometrical parameters. It is also capable of predicting the outgoing energy flux towards the material being processed, causing the temperature to rise along the material length.

The compaction roll can be modelled assuming isothermal conditions along its internal fluid section by ensuring a sufficient fluid flow, causing a temperature gradient along the compaction roll thickness. This assumption simplifies the heat transfer model for this element.

The proposed 1.5D heat transfer model for the automated tape-laying machine head can be used to simulate the temperature distribution along the processed material and its dynamics upon changes in the heating element input voltage and process speed, predicting the temperature along the heating zone domain.

The most relevant parameters that influence the machine behavior are the input voltage of the heating element, which increases the temperature of the processed composite material by directly heating its surface using radiation, and the process speed, which influences the material temperature through the transport effects.

The current machine configuration has an appropriate design and is capable of raising the material temperature to the required consolidation temperature value if a suitable control system is implemented.

With this model, which takes into account the thermal and optical properties of the material involved and their changes with temperature, a digital twin of the process can be formulated to develop control strategies using the machine head speed and the lamp power as the variables manipulated in order to control the nip point temperature. This model also allows one to estimate the composite temperature profile along the heating zone, acting as a supervisory function for a control system and allowing it to handle imposed constraints related to the material.

As the digital twin of the process is capable of estimating the composite temperature at the nip point, it lends itself to creating a temperature registry over time for further thermo-mechanical analysis for analyzing defects due to residual stress.

The digital twin model can be used for selecting the best process elements and their capabilities in terms of the heat source delivering capabilities, the process speed, and the mold temperature as a function of the composite material being processed in order to meet 
quality requirements of the final product. Thus, the study of those effects on an already built machine can be avoided and large time and economic benefits can be obtained.

Author Contributions: Conceptualization, J.d.S.R. and P.T.G.; methodology, J.d.S.R. and P.T.G.; software, J.d.S.R.; validation, J.d.S.R.; formal analysis, J.d.S.R. and P.T.G.; investigation, J.d.S.R.; resources, J.d.S.R.; data curation, J.d.S.R.; writing-original draft preparation, J.d.S.R. and P.T.G.; writing—review and editing, J.d.S.R., P.T.G., L.P. and F.G.d.A.; visualization, J.d.S.R.; supervision, L.P. and F.G.d.A; project administration, J.d.S.R.; funding acquisition, J.d.S.R. All authors have read and agreed to the published version of the manuscript.

Funding: This research has received funding from the European Union's Horizon 2020 research and innovation programme under grant agreement No 768710.

Institutional Review Board Statement: Not applicable.

Informed Consent Statement: Not applicable.

Data Availability Statement: Not applicable.

Conflicts of Interest: The authors declare no conflict of interest.

\section{References}

1. $\quad$ Engelhardt, R.; Ehard, S.; Wolf, T.; Oelhafen, J.; Kollmannsberger, A.; Drechsler, K. In Situ Joining of Unidirectional Tapes on Long Fiber Reinforced Thermoplastic Structures by Thermoplastic Automated Fiber Placement for Scientific Sounding Rocket Applications. Procedia CIRP 2019, 85, 189-194. [CrossRef]

2. Comer, A.J.; Ray, D.; Obande, W.O.; Jones, D.; Lyons, J.; Rosca, I.; O’Higgins, R.M.; McCarthy, M.A. Mechanical characterisation of carbon fibre-PEEK manufactured by laser-assisted automated-tape-placement and autoclave. Compos. Part A Appl. Sci. Manuf. 2015, 69, 10-20. [CrossRef]

3. Saenz-Castillo, D.; Martín, M.; Calvo, S.; Rodriguez-Lence, F.; Güemes, A. Effect of processing parameters and void content on mechanical properties and NDI of thermoplastic composites. Compos. Part A Appl. Sci. Manuf. 2019, 121, 308-320. [CrossRef]

4. Barakat, E.; Tannous, M. Simulation of the tape laying process with steering of tapes: Bonding defects prevention using simulation. In Proceedings of the 2019 Fourth International Conference on Advances in Computational Tools for Engineering Applications (ACTEA), Beirut, Lebanon, 3-5 July 2019 ; pp. 1-7. [CrossRef]

5. Crosky, A.; Grant, C.; Kelly, D.; Legrand, X.; Pearce, G. Fibre placement processes for composites manufacture. In Advances in Composites Manufacturing and Process Design; Elsevier: Amsterdam, The Netherlands, 2015; pp. 79-92. [CrossRef]

6. Khan, M.A.; Mitschang, P.; Schledjewski, R. Identification of some optimal parameters to achieve higher laminate quality through tape placement process. Adv. Polym. Technol. 2010, 29, 98-111. [CrossRef]

7. Liebsch, A.; Koshukow, W.; Gebauer, J.; Kupfer, R.; Gude, M. Overmoulding of consolidated fibre-reinforced thermoplastics increasing the bonding strength by physical surface pre-treatments. Procedia CIRP 2019, 85, 212-217. [CrossRef]

8. Tumkor, S.; Turkmen, N.; Chassapis, C.; Manoochehri, S. Modeling of heat transfer in thermoplastic composite tape lay-up manufacturing. Int. Commun. Heat Mass Transf. 2001, 28, 49-58. [CrossRef]

9. Martín, M.; Rodríguez-Lence, F.; Güemes, A.; Fernández-López, A.; Pérez-Maqueda, L.; Perejón, A. On the determination of thermal degradation effects and detection techniques for thermoplastic composites obtained by automatic lamination. Compos. Part A Appl. Sci. Manuf. 2018, 111, 23-32. [CrossRef]

10. Parlevliet, P.P.; Bersee, H.E.; Beukers, A. Residual stresses in thermoplastic composites - a study of the literature. Part III: Effects of thermal residual stresses. Compos. Part A Appl. Sci. Manuf. 2007, 38, 1581-1596. [CrossRef]

11. Sonmez, F.O.; Hahn, H.T. Modeling of Heat Transfer and Crystallization in Thermoplastic Composite Tape Placement Process. J. Thermoplast. Compos. Mater. 1997, 10, 198-240. [CrossRef]

12. Stokes-Griffin, C.M.; Compston, P.; Matuszyk, T.I.; Cardew-Hall, M.J. Thermal modelling of the laser-assisted thermoplastic tape placement process. J. Thermoplast. Compos. Mater. 2015, 28, 1445-1462. [CrossRef]

13. Schaefer, P.M.; Gierszewski, D.; Kollmannsberger, A.; Zaremba, S.; Drechsler, K. Analysis and improved process response prediction of laser- assisted automated tape placement with PA-6/carbon tapes using Design of Experiments and numerical simulations. Compos. Part A Appl. Sci. Manuf. 2017, 96, 137-146. [CrossRef]

14. Khan, M.A.; Mitschang, P.; Schledjewski, R. Tracing the Void Content Development and Identification of its Effecting Parameters during in Situ Consolidation of Thermoplastic Tape Material. Polym. Polym. Compos. 2010, 18, 1-15. [CrossRef]

15. Stokes-Griffin, C.; Compston, P. A combined optical-thermal model for near-infrared laser heating of thermoplastic composites in an automated tape placement process. Compos. Part A Appl. Sci. Manuf. 2015, 75, 104-115. [CrossRef]

16. Hosseini, S.M.A.; Baran, I.; van Drongelen, M.; Akkerman, R. On the temperature evolution during continuous laser-assisted tape winding of multiple C/PEEK layers: The effect of roller deformation. Int. J. Mater. Form. 2020, 14, 203-221 . [CrossRef]

17. Pitchumani, R.; Gillespie, J.W.; Lamontia, M.A. Design and Optimization of a Thermoplastic Tow-Placement Process with In-Situ Consolidation. J. Compos. Mater. 1997, 31, 244-275. [CrossRef] 
18. Pettersson, M.; Stenström, S. Modelling of an electric IR heater at transient and steady state conditions: Part I: Model and validation. Int. J. Heat Mass Transf. 2000, 43, 1209-1222. [CrossRef]

19. Pettersson, M.; Stenström, S. Modelling of an electric IR heater at transient and steady state conditions: Part II: Modelling a paper dryer. Int. J. Heat Mass Transf. 2000, 43, 1223-1232. [CrossRef]

20. Lichtinger, R.; Hörmann, P.; Stelzl, D.; Hinterhölzl, R. The effects of heat input on adjacent paths during Automated Fibre Placement. Compos. Part A Appl. Sci. Manuf. 2015, 68, 387-397. [CrossRef]

21. Belnoue, J.P.; Mesogitis, T.; Nixon-Pearson, O.J.; Kratz, J.; Ivanov, D.S.; Partridge, I.K.; Potter, K.D.; Hallett, S.R. Understanding and predicting defect formation in automated fibre placement pre-preg laminates. Compos. Part A Appl. Sci. Manuf. 2017, 102, 196-206. [CrossRef]

22. Colton, J.; Leach, D. Processing parameters for filament winding thick-section PEEK/carbon fiber composites. Polym. Compos. 1992, 13, 427-434. [CrossRef]

23. Di Francesco, M.; Veldenz, L.; Dell'Anno, G.; Potter, K. Heater power control for multi-material, variable speed Automated Fibre Placement. Compos. Part A Appl. Sci. Manuf. 2017, 101, 408-421. [CrossRef]

24. Silex. Silicone Rubber Sheeting High Temperature Solid, Datasheet. 2019. Available online: https://www.silex.co.uk/media/38 087/solid-sheet-thtsilex-ntds.pdf (accessed on 2 February 2019).

25. Narnhofer, M.; Schledjewski, R.; Mitschang, P.; Perko, L. Simulation of the Tape-Laying Process for Thermoplastic Matrix Composites. Adv. Polym. Technol. 2013, 32, E705-E713. [CrossRef]

26. Chinesta, F.; Leygue, A.; Bognet, B.; Ghnatios, C.; Poulhaon, F.; Bordeu, F.; Barasinski, A.; Poitou, A.; Chatel, S.; Maison-Le-Poec, S. First steps towards an advanced simulation of composites manufacturing by automated tape placement. Int. J. Mater. Form. 2014, 7, 81-92. [CrossRef]

27. Incropera, F.P.; DeWitt, D.P.; Bergman, T.L.; Lavine, A.S. Fundamentals of Heat and Mass Transfer 6th Edition; John Wiley \& Sons: Hoboken, NJ, USA, 2007. [CrossRef]

28. Howell, J.; Menguc, M.; Siegel, R. Thermal Radiation Heat Transfer; CRC Press: Boca Raton, FL, USA, 2015.

29. Modest, M. Radiative Heat Transfer, 3rd ed.; Academic Press: Cambridge, MA, USA, 2013; p. 904.

30. Shapiro, A. FACET: A Radiation View Factor Computer Code for Axisymmetric, 2D Planar, and 3D Geometries with Shadowing; Lawrence Livermore National Lab.: Livermore, CA, USA, 1983.

31. Pettersson, M. Heat Transfer and Energy Efficiency in Infrared Paper Dryers. Ph.D. Thesis, Lund University, Lund, Sweden, 1999

32. Forsythe, W.E.; Adams, E.Q. Radiating Characteristics of Tungsten and Tungsten Lamps A Correction. J. Opt. Soc. Am. 1945, 35, 306. [CrossRef]

33. Izuegbu, N.S.; Adonis, M.L. Simulation and modelling of energy efficient design of a ceramic infrared heater. In Proceedings of the 2011 8th Conference on the Industrial and Commercial Use of Energy, ICUE 2011, Cape Town, South Africa, 16-17 August 2011; pp. 69-74.

34. Lampinen, M.J.; Ojala, K.T.; Koski, E. Modeling and measurements of infrared dryers for coated paper. Dry. Technol. 1991, 9, 973-1017. [CrossRef]

35. Venkateshan, S. Heat Transfer; Springer International Publishing: Cham, Switzerland, 2021; pp. 160-189. [CrossRef]

36. Feingold, A.; Gupta, K.G. New analytical approach to the evaluation of configuration factors in radiation from spheres and infinitely long cylinders. J. Heat Transf. 1970, 92, 69-76. [CrossRef]

37. Domalski, E.S. NIST Chemistry WebBook. 2011. Available online: https: / webbook.nist.gov/ (accessed on 7 January 2022).

38. Bansal, N.P. Handbook of Glass Properties; Elsevier: Amsterdam, The Netherlands, 1986; p. 680. [CrossRef]

39. Sergeev, O.A.; Shashkov, A.G.; Umanskii, A.S. Thermophysical properties of quartz glass. J. Eng. Phys. 1982, $43,1375-1383$. [CrossRef]

40. Chase, M.W.; Curnutt, J.L.; Downey, J.R.; McDonald, R.A.; Syverud, A.N.; Valenzuela, E.A. JANAF Thermochemical Tables, 1982 Supplement. J. Phys. Chem. Ref. Data 1982, 11, 695-940. [CrossRef]

41. Gale, W.F.; Totemeier, T.C. Smithells Metals Reference Book, 8th ed.; Elsevier: Amsterdam, The Netherlands, 2003; Volume 1, p. 2080.

42. Lide, D.R. (Ed.) CRC Handbook of Chemistry and Physics, 84th ed.; CRC Press LLC: Boca Raton, FL, USA, 2003. p. 2616, ISBN 0-8493-0484-9.

43. Hust, J.G.; Lankford, A.B. Thermal Conductivity of Aluminium, Copper, Iron, and Tungsten for Temperatures from 1 K to the Melting Point; Number June; U.S. Department of Commerce: Washington, DC, USA, 1984; p. 266.

44. Edwards, T.C.; Steer, M.B. Foundations for Microstrip Circuit Design, 4th ed.; John Wiley \& Sons: Hoboken, NJ, USA, 2016.

45. Wentink, T.; Planet, W.G. Infrared Emission Spectra of Quartz. J. Opt. Soc. Am. 1961, 51, 595. [CrossRef]

46. Toray Group. Nylon 6-Based Thermoplastic Composite. 2019. Available online: https://www.toraytac.com/media/694245aa-37 65-43b4-a2cd-8cf76e4aeec5/lmhIVg/TAC/Documents/Data_sheets/Thermoplastic/UD\%20tapes, \%20prepregs \%20and \%20 laminates/Toray-Cetex-TC910_PA6_PDS.pdf (accessed on 6 January 2022).

47. ASTM E 1269-9901. Standard Test Method for Determining Specific Heat Capacity by Differential Scanning Calorimetry; ASTM: West Conshohocken, PA, USA, 2001.

48. Zhai, S.; Zhang, P.; Xian, Y.; Zeng, J.; Shi, B. Effective thermal conductivity of polymer composites: Theoretical models and simulation models. Int. J. Heat Mass Transf. 2018, 117, 358-374. [CrossRef]

49. Villière, M.; Lecointe, D.; Sobotka, V.; Boyard, N.; Delaunay, D. Experimental determination and modeling of thermal conductivity tensor of carbon/epoxy composite. Compos. Part A Appl. Sci. Manuf. 2013, 46, 60-68. [CrossRef] 
50. Betta, G.; Rinaldi, M.; Barbanti, D.; Massini, R. A quick method for thermal diffusivity estimation: Application to several foods. J. Food Eng. 2009, 91, 34-41. [CrossRef]

51. Yang, C.Y. Estimation of the temperature-dependent thermal conductivity in inverse heat conduction problems. Appl. Math. Model. 1999, 23, 469-478. [CrossRef]

52. Optris. Compact IR Pyrometer for OEM Applications: Optris CS LT. 2021. Available online: https://www.optris.global/optriscs-lt-csmed-1t (accessed on 6 January 2022).

53. Hairer, E.; Wanner, G. Solving Ordinary Differential Equations II; Springer Series in Computational Mathematics; Springer: Berlin/Heidelberg, Germany, 1996; Volume 14. [CrossRef] 